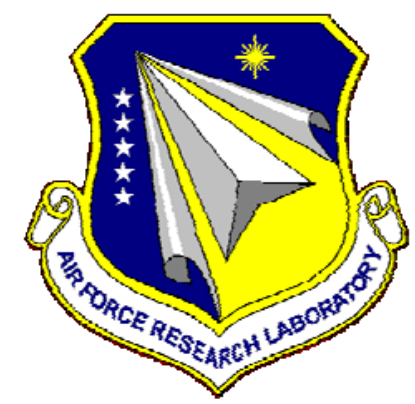

\title{
AFRL-RX-WP-TR-2015-0030
}

\section{MANUFACTURING TECHNOLOGY SUPPORT (MATES II) \\ Task Order 0005: Manufacturing Integration and Technology \\ Evaluation to Enable Technology Transition \\ Subtask Phase 0 Study Task: Manufacturing Technology (ManTech) and Systems Engineering For Quick Reaction Systems}

Bradford A. Cowles and Daniel G. Backman

Cowles Consulting, LLC

OCTOBER 2014

Interim Report

Distribution Statement A. Approved for public release, distribution unlimited.

See additional restrictions described on inside pages

\section{STINFO COPY}

AIR FORCE RESEARCH LABORATORY MATERIALS AND MANUFACTURING DIRECTORATE WRIGHT-PATTERSON AIR FORCE BASE, OH 45433-7750 AIR FORCE MATERIEL COMMAND UNITED STATES AIR FORCE 


\section{NOTICE AND SIGNATURE PAGE}

Using Government drawings, specifications, or other data included in this document for any purpose other than Government procurement does not in any way obligate the U.S. Government. The fact that the Government formulated or supplied the drawings, specifications, or other data does not license the holder or any other person or corporation; or convey any rights or permission to manufacture, use, or sell any patented invention that may relate to them.

This report was cleared for public release by the USAF 88th Air Base Wing (88 ABW) Public Affairs Office (PAO) and is available to the general public, including foreign nationals.

Copies may be obtained from the Defense Technical Information Center (DTIC) (http://www.dtic.mil).

AFRL-RX-WP-TR-2015-0030 HAS BEEN REVIEWED AND IS APPROVED FOR PUBLICATION IN ACCORDANCE WITH ASSIGNED DISTRIBUTION STATEMENT.

//SIGNATURE//

MARY E. KINSELLA

Project Engineer

Propulsion, Structures and

Manufacturing Enterprise Branch
//SIGNATURE//

HOWARD W. SIZEK

Branch Chief

Propulsion, Structures and

Manufacturing Enterprise Branch

This report is published in the interest of scientific and technical information exchange, and its publication does not constitute the Government's approval or disapproval of its ideas or findings. 


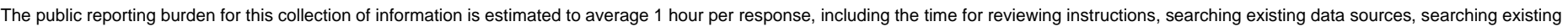

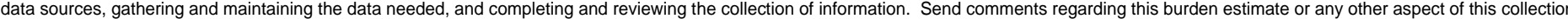

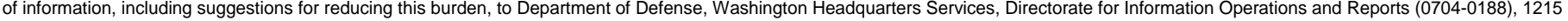

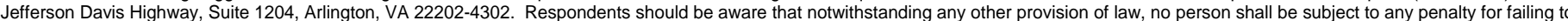
comply with a collection of information if it does not display a currently valid OMB control number. PLEASE DO NOT RETURN YOUR FORM TO THE ABOVE ADDRESS.
1. REPORT DATE (DD-MM-YY)
2. REPORT TYPE
October 2014
2. REPORT TYPE
3. DATES COVERED (From - To)
2 January 2014 - 30 September 2014

\section{TITLE AND SUBTITLE}

MANUFACTURING TECHNOLOGY SUPPORT (MATES II)

Task Order 0005: Manufacturing Integration and Technology Evaluation to

Enable Technology Transition

Subtask Phase 0 Study Task: Manufacturing Technology (ManTech) and Systems Engineering For Quick Reaction Systems

6. AUTHOR(S)

Bradford A. Cowles and Daniel G. Backman

5a. CONTRACT NUMBER

FA8650-11-D-5702-0005

5b. GRANT NUMBER

5c. PROGRAM ELEMENT NUMBER

63680F

5d. PROJECT NUMBER

5280

5e. TASK NUMBER

00

5f. WORK UNIT NUMBER

X028

7. PERFORMING ORGANIZATION NAME(S) AND ADDRESS(ES)

FOR: General Dynamics

\begin{tabular}{l|c} 
Compass Technology Group & FOR: General Dynamics \\
Information Technology \\
Marietta GA 30062
\end{tabular}$\quad \begin{gathered}5100 \text { Springfield Pike, Suite } 509 \\
\text { Dayton OH 45431 }\end{gathered}$

9. SPONSORING/MONITORING AGENCY NAME(S) AND ADDRESS(ES)

Air Force Research Laboratory

Materials and Manufacturing Directorate

Wright-Patterson Air Force Base, OH 45433-7750

Air Force Materiel Command

United States Air Force

8. PERFORMING ORGANIZATION REPORT NUMBER

12. DISTRIBUTION/AVAILABILITY STATEMENT

Distribution Statement A: Approved for public release (PA); distribution unlimited.

13. SUPPLEMENTARY NOTES

PA Case No. 88ABW-2014-5688, Date Cleared: December 3, 2014. This document contains color.

14. ABSTRACT (Maximum 200 words)

AFRL desires to develop a recommended process and associated guideline document supporting more rapid maturation and risk reduction for new Manufacturing Technologies (MT). AFRL sponsored a 6 month study task to make an initial assessment of promising tools and methods, formulate a high-level technical strategy, and generate an initial outline of a guideline document. Six candidate topic areas were identified for further evaluation, and proposed activities were defined and integrated with the current MRL/MRA process. The proposed approach advocates an additional Manufacturing Thread in the MRL process: "Systems Engineering for Manufacturing Technology.” The recommended activities were integrated into six sub-threads, and aligned with MRL gate criteria. Alternatively, proposed activities could be implemented as a Recommended Best Practice. It is believed that these activities, when employed in an integrated manner, could effectively accelerate the maturation of new Manufacturing Technologies, and reduce the risk associated with implementation.

15. SUBJECT TERMS

manufacturing technology, integrated computational materials engineering (ICME), variation, expert elicitation, risk assessment, manufacturing readiness level (MRL)

\begin{tabular}{|l|l|l|c|c|c|}
\hline \multicolumn{2}{|l|}{$\begin{array}{l}\text { 16. SECURITY CLASSIFICATION OF: } \\
\text { 17. LIMITATION } \\
\text { OF ABSTRACT: }\end{array}$} & $\begin{array}{c}\text { 18. NUMBER } \\
\text { OF PAGES }\end{array}$ & $\begin{array}{l}\text { 19a. NAME OF RESPONSIBLE PERSON (Monitor) } \\
\text { Mary Kinsella }\end{array}$ \\
\cline { 1 - 2 } $\begin{array}{c}\text { a. REPORT } \\
\text { Unclassified }\end{array}$ & $\begin{array}{l}\text { b. ABSTRACT } \\
\text { Unclassified }\end{array}$ & $\begin{array}{l}\text { c. THIS PAGE } \\
\text { Unclassified }\end{array}$ & SAR & 65 & $\begin{array}{c}\text { 19b. TELEPHONE NUMBER (Include Area Code) } \\
937-904-4389\end{array}$ \\
\hline
\end{tabular}




\section{TABLE OF CONTENTS}

Section

Page

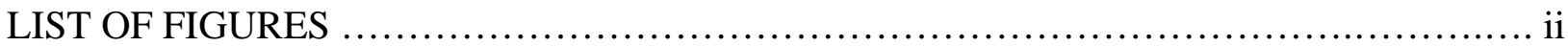

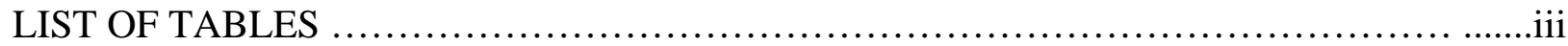

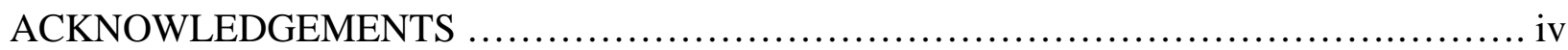

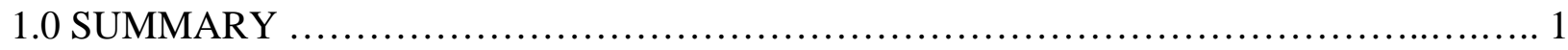

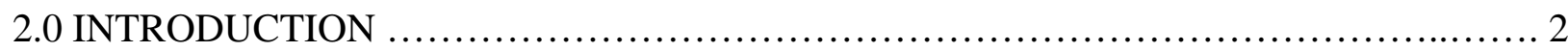

3.0 METHODS, ASSUMPTIONS, AND PROCEDURES ............................... 5

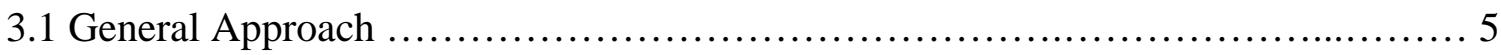

3.2 High Level Context and the Current MRL/MRA Process ........................ 6

3.3 Review of MRL and MRA Process ......................................... 9

3.4 Historical Examples ..................................................... 12

3.5 Early Risk Identification and Mitigation ................................... 14

3.6 Focus Areas Identified for Evaluation ...................................... 17

3.6.1 Expert Elicitation ........................................... 17

3.6.2 Computational Models for Materials, Manufacturing

Technology, and Processes ...................................... 19

3.6.3 Feedback and Updating Processes ................................ 23

3.6.4 In-Process Monitoring and Advanced Inspection Techniques ........... 24

3.6.5 Definition and Execution of Critical Experiments .................... 24

3.6.6 Other Considerations ........................................... 25

4.0 RESULTS AND DISCUSSION ............................................. 26

4.1 Concept of SEMT and General Alignment with MRL ......................... 26

4.2 Proposed Systems Engineering for Manufacturing Technology (SEMT) .......... 29

4.2.1 Sub-thread 1: Technical Risk and Knowledge Assessment .............. 30

4.2.2 Sub-thread 2: Integrated Computational Materials Engineering ......... 32

4.2.3 Sub-thread 3: Verification and Validation and Tool Maturity Level...... 34

4.2.4 Sub-thread 4: Definition and Execution of Critical Experiments .......... 36

4.2.5 Sub-thread 5: Process Capability, Control, \& Quality Management........37

4.2.6 Sub-thread 6: Manufacturing Management, Workforce

Development, and Resources ....................................... 39

4.3 Alignment of SEMT with the MRL Process and Manufacturing Threads ............ 41

4.4 Recommended Decision Questions for When to Employ SEMT ................ 43

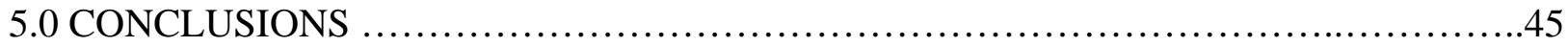

6.0 RECOMMENDATIONS .................................................... 48

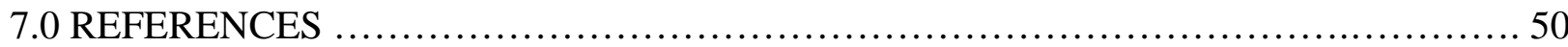

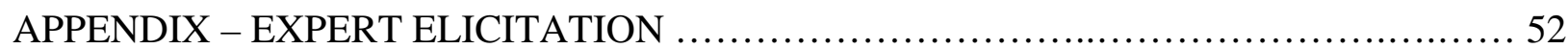

LIST OF SYMBOLS, ABBREVIATIONS, AND ACRONYMS ........................... 58

i

Distribution Statement A. Approved for public release (PA); distribution unlimited. 


\section{LIST OF FIGURES}

Figure

Page

1 Defense Acquisition Process Sequence and Milestones.............................. 6

2 MRL and TRL Gates in Relation to Acquisition Phases and Milestones.................. 7

3 Defense Acquisition Process Sequence and Milestones for "Model 1 Hardware Intensive Program,” from Interim DODI 5000.02 (Nov 2013) ............... 8

4 Defense Acquisition Process Sequence and Milestones for "Model 4 Accelerated Acquisition Program,” from Interim DODI 5000.02 (Nov 2013)............ 9

5 Diagram showing an idealized manufacturing process under development and the associated development and control deficiencies that can increase risk .......... 15

6 Outline of benefits that expert elicitation provides to an MT development effort....... 19

7 Concept Illustration of Proposed SEMT Activities in Current MRL Process............ 28

8 Schematic illustration shows the proposed SEMT thread and its six Sub-threads (light green color) inserted within the MRL threaded matrix ....................... 30

9 Alignment of Proposed SEMT Thread and Six Sub-threads with MRL Gates.......... 42

A-1 The PIRT ranking table................................................... 54

A-2 The PIRT ranking table plots "importance ranking” and "uncertainty ranking” ........ 55

A-3 Typical chart used to tabulate FMECA results and then calculate analysis .............. 56

ii

Distribution Statement A. Approved for public release (PA); distribution unlimited. 


\section{LIST OF TABLES}

Table $\quad$ Page

1 Summary of prospective benefits and risks encountered for four historical manufacturing development M\&P programs.................................... 13

2 SEMT Focus areas consolidated as Sub-threads in relation to MRL and Current Manufacturing Threads ............................................... 27

3 Technical Risk and Knowledge Assessment Sub-thread and MRL Alignment ......... 32

$4 \quad$ ICME Sub-thread and MRL Alignment......................................... 34

$5 \quad$ V\&V and TML Sub-thread and MRL Alignment................................... 35

6 Critical MT Experiments Sub-thread and MRL Alignment.......................... 37

$7 \quad$ Process Capability, Control and Quality Management Sub-thread and

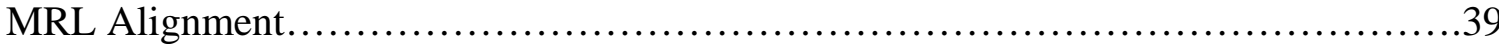

8 Manufacturing Management, Workforce Development, and Resources Sub-thread and MRL Alignment .......................................... 40

$9 \quad$ Proposed Decision Questionnaire for Use of SEMT Process.......................... 44 


\section{ACKNOWLEDGEMENTS}

The authors would like to acknowledge several key individuals who contributed to the successful completion of this project. Specifically, Dr. Rollie Dutton of AFRL/RXM for his guidance during planning and execution of the study task, Drs. Mary Kinsella, Howard Sizek, Karla Strong, and Kermit Sterns of AFRL for their feedback and contributions, Gary Stanley and Jim Morgan for their guidance on current MRL and MRA processes. In addition, Gene Wiggs of GE and Paul Hauwiller of General Dynamics Information Technology (GDIT) provided valuable feedback during execution of the study task and formulation of the recommendations. 


\subsection{SUMMARY}

Recent advances in Integrated Computational Materials Engineering (ICME), and manufacturing process models, along with increased use of probabilistic methods and uncertainty quantification can be applied to accelerate maturation of new manufacturing processes and technology. Combined with new processes to identify, assess, and address technology risks during development, it is believed that significant acceleration in technology maturation can be achieved. Rapid maturation and qualification would enable more effective transition of technology into production use for new systems, enable faster, more capable response to design changes, and reduce risk of insertion of new materials and manufacturing processes. These goals are consistent with, and supportive of, Air Force Research Laboratories (AFRL) strategic initiatives, including Moving Manufacturing Left, Agile Manufacturing, and Digital Thread.

AFRL desires to develop a recommended process and associated guideline document supporting more rapid maturation and risk reduction for new Manufacturing Technologies (MT), including the recommended application of promising tools and methods. This effort was expected to be especially relevant to future "quick reaction systems," where total development time may be reduced, and also to future systems where total unit production may be relatively low. To this end, the Manufacturing Technology Directorate at the Air Force Research Laboratories (AFRL/RXM) sponsored a six month "Phase 0" study task to make an initial assessment of promising tools and methods, formulate a high-level technical strategy, and generate an initial outline of a guideline document supporting the rapid maturation and risk reduction for new manufacturing technologies.

The study task identified candidate topic areas for further evaluation, and then proposed an approach to integrate these activities with the current MRL/MRA process. The proposed approach advocates an additional Manufacturing Thread in the MRL process: "Systems Engineering for Manufacturing Technology.” This proposed thread consists of six integrated sub-threads, comprising the promising tools and methods that were identified and evaluated under the study task. Alternatively, the proposed activities could be developed into a "best practice," a recommended procedure, or an engineering work instruction. Proposed activities were defined, sequenced, and aligned with MRL gates. It is thought that these activities, when employed in an integrated manner, could effectively accelerate the maturation of new Manufacturing Technologies, and reduce the risk associated with implementation. This report summarizes results of the study task. 


\subsection{INTRODUCTION}

Development, certification and sustainment of Department of Defense (DoD) weapon systems are lengthy, expensive processes, which often require iterations in design configuration or changes in materials or manufacturing processes during development. Development of new technology is not always in sync with schedule requirements for system acquisition, inhibiting insertion. This is especially true for new manufacturing processes and technology, where lack of prior production experience increases risk and inhibits commitment to new processes and technology, resulting in significant missed opportunity. Future DoD requirements may exacerbate these issues. Demand for "quick reaction systems" - where intent is to rapidly develop new systems, as well as systems specifically designated for "accelerated acquisition," and the likelihood that many new systems will have limited unit production requirements, will all challenge the legacy technology development and implementation processes.

Recent advances in Integrated Computational Materials Engineering (ICME), in manufacturing process models, and increased use of probabilistic methods and uncertainty quantification may enable accelerated maturation of new manufacturing processes and technology. Combined with new processes to identify, assess, and address technology risks during development, it is believed that significant acceleration in technology maturation can be achieved. Rapid maturation and qualification would enable more effective transition of technology into production use for new systems, enable faster, more capable response to design changes, and reduce risk of insertion of new materials and manufacturing processes. These goals are believed to be consistent with, and supportive of, DoD and AFRL strategic initiatives, including Engineered Resilient Systems, Moving Manufacturing Left, Agile Manufacturing, and Digital Thread.

AFRL desires to develop a recommended process and associated guideline document supporting more rapid maturation and risk reduction for new manufacturing technologies (MT), including the recommended application of promising tools and methods. To this end, AFRL sponsored a study task to make an initial assessment of promising tools and methods, formulate a high-level technical strategy, and generate an initial outline of a guideline document supporting the rapid maturation and risk reduction for new manufacturing technologies (MT). The study effort was organized into three tasks:

- Task 1: Analysis of Background Information

- Task 2: Identification of Methods to Accelerate MT Maturation and Risk Reduction

- Task 3: Formulation of an Initial Guideline Process and Associated Research Plan

The objective of Task 1 was to review methods and guidelines that the Department of Defense (DoD) currently employs to assess MT development and maturation. These methods and guidelines included the Defense Acquisition Guidebook (DAG), and DoD Instruction 5000.02 for highest level context, and Manufacturing Readiness Levels (MRLs) and associated Manufacturing Readiness Assessments (MRAs) for practical, application level guidelines. In addition, relevant team processes available in the open literature for risk assessment and mitigation, including "expert elicitation" and subject matter expert (SME) review processes were assessed for relevance. Key issues and challenges associated with the rapid maturation and risk

Distribution Statement A. Approved for public release (PA); distribution unlimited. 
reduction of new manufacturing processes were also reviewed in the context of a few selected prior MT programs. The intent was to frame and focus efforts planned in Tasks 2 and 3 of this study.

Several candidate topics were identified for further consideration and assessment under the study task:

- Early risk identification and mitigation approaches

- Increased use of computational modeling for materials and processes (ICME), including empirically based modeling

- Verification and Validation methods for such modeling

- Uncertainty Quantification and probabilistic assessments

- Feedback and updating methods for refining models based on early data

- Increased use of in-process monitoring and advanced inspection methods for process monitoring and control

- Definition and execution of critical experiments.

The candidate topics were evaluated and refined, in the context of the current MRL/MRA process and the associated Manufacturing Threads that have been defined. It should be noted that in several cases, the recommended activities list associated with the "manufacturing threads" already contain or infer some of the items identified for further assessment under this study task, although in current practice these items are generally not well defined and occur later in the process than would be most effective.

One key conclusion was that these topics - both strategies and methods - would be most effective when employed early in an integrated, iterative, and collective manner. They would not be nearly as effective if applied individually or independently. A conceptual framework was developed to illustrate where in the MRL/MRA process these methods should be applied.

The current MRL/MRA process is well defined and accepted; it is also comprehensive in both scope and application. When properly practiced, it effectively assesses and reduces implementation risks for new manufacturing technologies. The most significant challenge for this Study Task was to identify, define, and recommend processes and/or methods that could effectively accelerate maturation of manufacturing technologies, and to provide confidence to key decision-makers that such technologies could be successfully implemented, with an acceptable level of risk.

The identified topic areas were incorporated in Task 3 efforts: Formulation of an Initial Guideline Process and Associated Research Plan. The objectives of Task 3 were to refine and expand upon the candidate topics previously identified, and to outline an initial guideline process for implementation. The approach was to identify recommended activities, supporting methods, tools and references, and relate these to the current MRL process. Feedback from several AFRL and industry experts was also received and incorporated. The results were used to generate a suite of recommended activities, which were consolidated into a framework and integrated with the current MRL/MRA process. In addition, a proposed set of questions was developed to assist assessment of when such activities would be appropriate. The result is a recommendation that 
one additional Manufacturing Thread be considered for inclusion in the MRL/MRA framework: “Systems Engineering for Manufacturing Technology (SEMT)" This

recommended additional Manufacturing Thread consists of six (6) sub-threads, which contain the recommended activities and the proposed linkage to the MRL/MRA process. The recommendations are believed compatible and aligned with the current process. Alternatively, the recommended activities under SEMT could readily be adapted as a "Recommended Best Practice," or as a program or engineering work instruction, as the proposed activities are aligned and entirely consistent with the current MRL/MRA process. 


\subsection{METHODS, ASSUMPTIONS, AND PROCEDURES}

\subsection{General Approach}

The objectives of the study task were to develop a recommended process and associated guideline document supporting more rapid maturation and risk reduction for new manufacturing technologies (MT), including the recommended application of promising tools and methods. These tools and methods were to include increased use of computational models, the associated verification and validation processes needed to ensure confidence in such models, increased use of uncertainty quantification and probabilistic methods, and increased development and use of in-process monitoring and control. In addition, the study task was intended to explore methods and processes to identify technology and development risks early, and to develop risk mitigation plans as appropriate. The general approach that was taken consisted of three sequential tasks:

- Analysis of Background Information

- Identification of Methods to Accelerate MT Maturation and Risk Reduction

- Formulation of an Initial Guideline Process and Associated Research Plan

Under the first task, current DoD and USAF processes for system acquisition and manufacturing technology development were reviewed. These included the Defense Acquisition Guidebook (DAG), and DoD Instruction 5000.02 for highest level context, and Manufacturing Readiness Levels (MRLs) and associated Manufacturing Readiness Assessments (MRAs) for practical, application level guidelines.

Under the second task, candidate tools and methods were identified and evaluated that were believed capable of accelerating the maturation of new manufacturing technologies, and reducing risk of insertion. The resulting topics, which were listed in the Introduction section, above, were reviewed in some detail. Descriptions of activities and rationale for use were generated, and literature references were provided as appropriate.

The approach taken under the third task was to consolidate the activities associated with these topics into an integrated suite of recommended activities, in a manner that would be fully aligned and consistent with the current MRL/MRA process. Specific recommended activities were defined, sequenced, and aligned with recommended MRL gates. The result is a recommendation that one additional Manufacturing Thread be considered for inclusion in the MRL/MRA framework: "Systems Engineering for Manufacturing Technology (SEMT)" This recommended additional Manufacturing Thread consists of six (6) sub-threads, which contain the recommended activities and the proposed linkage to the MRL/MRA process. The recommendations are believed compatible and aligned with the current process. Alternatively, the recommended activities under SEMT could readily be adapted as a "Recommended Best Practice" or an engineering instruction or guideline, as the proposed activities are aligned and entirely consistent with the current MRL/MRA process. 


\subsection{High Level Context and the Current MRL/MRA Process}

The approach selected was to review current guidelines and practices used for assessment and decision-making relative to materials and manufacturing technologies, specifically for those associated with structural applications in aerospace systems. With the intent to ensure proper context, the starting point for this review was the general acquisition process used by the Department of Defense (DoD) for weapons systems. The acquisition process for such an enormous breadth of applications is, of course, extraordinarily large and complex. It was also recognized that these processes are also intended for application at the system level, and most often for major weapons systems or acquisitions. The latest guidelines, which are summarized in the Defense Acquisition Guidebook [1], provides guidance and reference paths for many key activities and decision processes which are generically applicable to DoD weapons system acquisition. It addresses both the pre-acquisition and acquisition phases in the weapons system life cycle. Relevant reference material for this study task was found in Chapter 4 - Systems Engineering. Specifically, within the Milestone A and Technology Development phase write-up in Section 4.2.4, use of Technology Readiness Assessment (TRA) was cited. Later, in Section 4.2.5 pertaining to Milestone $B$ and the Engineering and Manufacturing Development phase (EMD), the MRL Deskbook and use of Manufacturing Readiness Levels (MRL) was cited as "one source" for how to assess manufacturing and production readiness. The references in the Defense Acquisition Guidelines were not at all specific in terms of methods and processes that were recommended for technology or manufacturing readiness assessment or management.

The DAG guidelines do, however, reference the DoD instruction DODI 5000.02 [2] for detailed requirements, specific statutory requirements, and connectivity between Defense Acquisition Milestones (eg: Milestones A, B, and C), program needs, and the assessment and management of program technical risks. The generic sequence of program phases, key milestones, and associated supporting milestones are shown in Figure 1, as extracted directly from DODI 5000.02 .

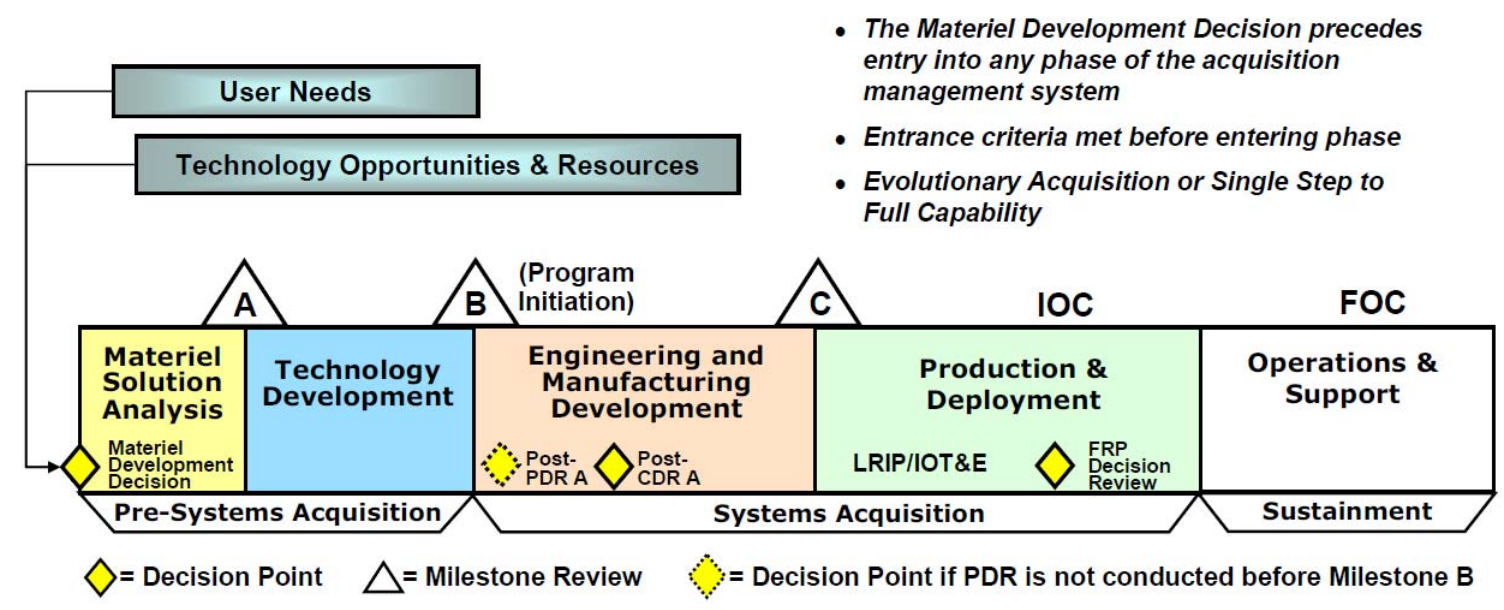

Figure 1: Defense Acquisition Process Sequence and Milestones from DODI5000.02 (Dec 2008)

6

Distribution Statement A. Approved for public release (PA); distribution unlimited. 
Technology and Manufacturing Readiness Levels have been linked to the acquisition process and milestones shown in Figure 1. In general, it has been interpreted that both Technology and Manufacturing Readiness Levels of 6 are required for a new technology or manufacturing process prior to Defense Acquisition Milestone B, which marks the beginning of the Engineering and Manufacturing Development phase (EMD), where detailed design commences. In addition, TRL and MRL-4 has been linked to Milestone A, the beginning of the Technology Development Phase, and MRL-8 with Milestone C, the beginning of the Production and Deployment Phase, where Low Rate Initial Production (LRIP) is initiated for major weapons systems. The TRL and MRL gates are shown in relation to the Defense Acquisition System milestones in Figure 2, below.

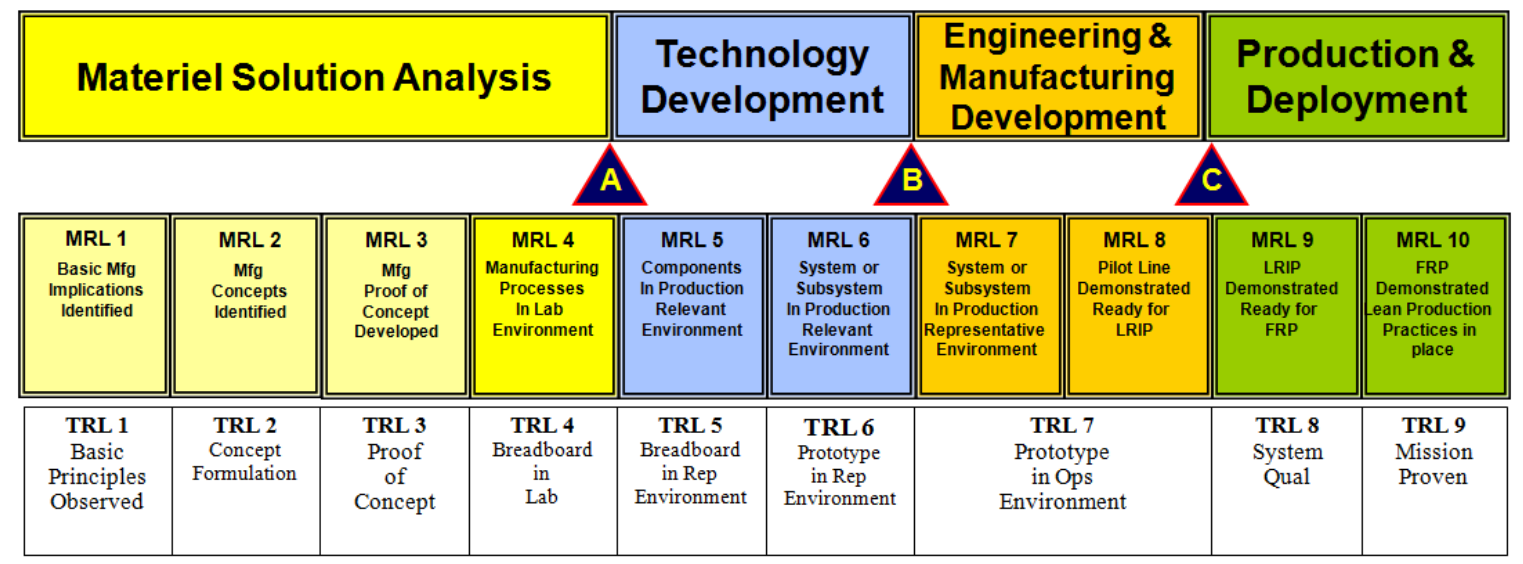

Figure 2: MRL and TRL Gates in Relation to Acquisition Phases and Milestones

In actual practice, many if not all programs have one or more technologies that are not considered "mature" (TRL/MRL-6 or greater) at commencement of Milestone B. A 2006 study by the GAO [3] found that this was the case for a majority of major weapons systems: that immature technologies were related to future cost and schedule growth, and that if a program was launched with "immature" technologies, these issues would persist. GAO advocated utilization of "knowledge based" decision points for assessing both technologies (at Milestone B) and production readiness (at Milestone C). GAO issued many related studies in subsequent years, some of which specifically recognize and recommend use of the TRL and MRL processes. One of particular interest is GAO-10-439 [4], which contains specific recommendations that DoD adopt wide use of MRLs: "GAO recommends that the Secretary of Defense require the use of MRLs across DOD programs, strengthen the MRL criteria (process control) for production start, assess the need for tools, and assess the manufacturing workforce to address knowledge gaps.”

Very recently, Deputy Secretary of Defense Ashton B. Carter cancelled DODI 5000.02 in its entirety (excepting Enclosure 9) and then replaced it with Interim DODI 5000.02 [5]. The new interim document contained some significant changes, which are described briefly here due to their perceived relevance to the goals and approach of this study task. Specifically, Interim DODI 5000.02 describes four basic models as well as hybrid combinations for the acquisition process and sequence, as compared with a single model shown in the previous version of DODI 5000.02 (see Figure 1, above). The apparent intent is to increase flexibility in the acquisition process and tailor requirements to specific program needs, as permitted within statutory

Distribution Statement A. Approved for public release (PA); distribution unlimited. 
requirements. Two of the four models are regarded especially relevant to the study task: Model 1: Hardware Intensive Program, and Model 4: Accelerated Acquisition Program. The remaining models were for software intensive programs and hybrid combinations.

The graphical depiction of Model 1: Hardware Intensive Program is shown in Figure 3, below. Comparison with the acquisition process management chart previously presented in Figure 1 shows significant differences in that the transition line between phases is no longer clearly defined, and related activity is shown before and after key milestones B and C, as well as in transition from low rate to full production.

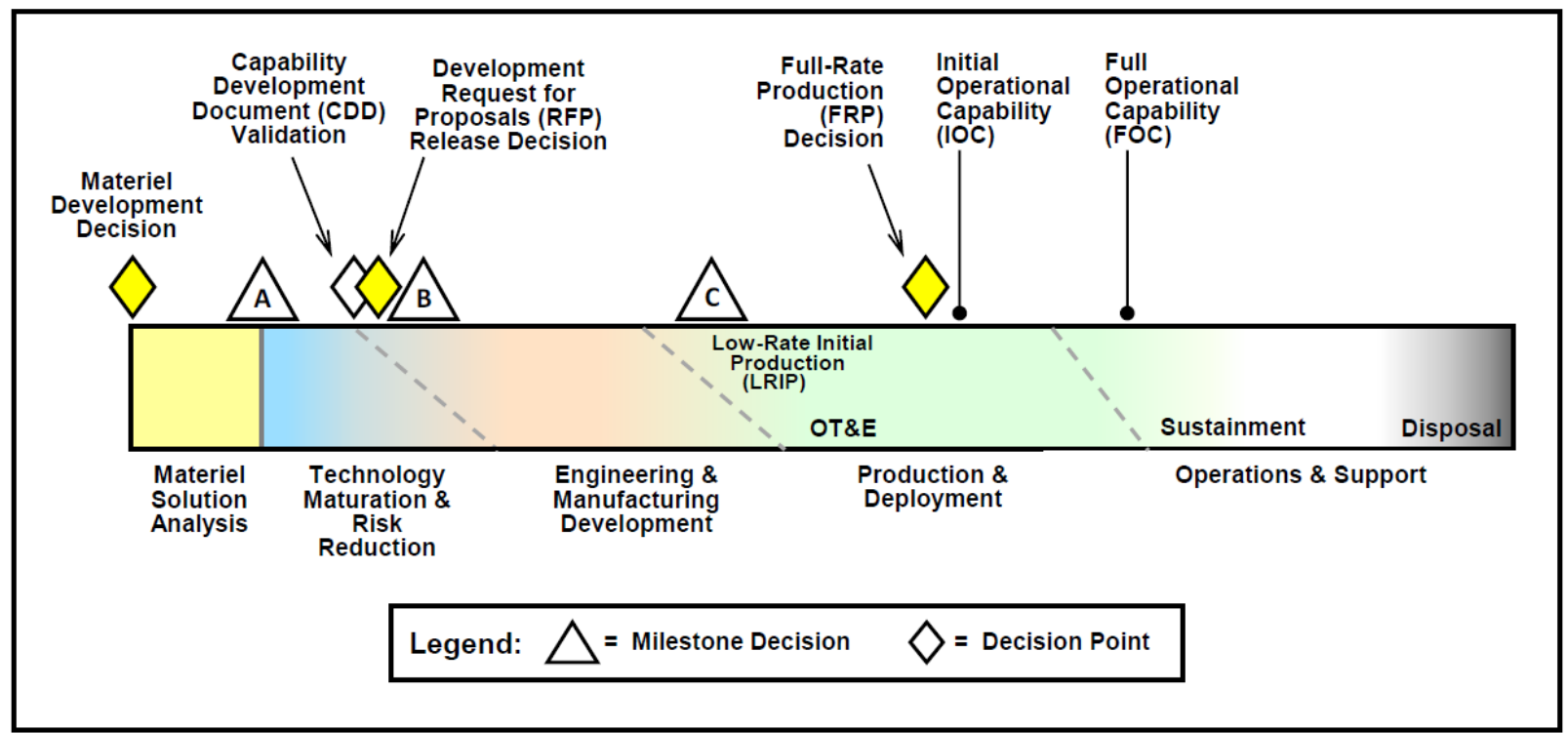

Figure 3: Defense Acquisition Process Sequence and Milestones for "Model 1 Hardware Intensive Program,” from Interim DODI 5000.02 (Nov 2013)

The graphical depiction of Model 4: Accelerated Acquisition Program is presented in Figure 4. It shows even more striking changes from Figure 1: Milestones A and B are essentially concurrent, and it shows that technology and manufacturing process development will occur concurrently with Engineering and Manufacturing Development.

Programs following this acquisition management model will undoubtedly require additional focus on assessment and mitigation of program risks posed by technology and manufacturing readiness.

This summary of methods and guidelines that DoD currently employs to manage weapons system development and acquisition was clearly at a high-level - certainly at the systems level, and generally most applicable for major systems. The recently defined (or modified) acquisition models are regarded especially relevant to provide guidance to the study task, since the goal of the current study task is to identify potential tools and methods to accelerate manufacturing technology maturation, and to reduce program risk of implementation. It is not known at this time whether (or exactly how) the changes contained in Interim DODI 5000.02 will affect the application and use of the TRL and MRL processes in the future. However, the objectives of this study task seem to be well-aligned to support the changes in Interim DODI 5000.02.

Distribution Statement A. Approved for public release (PA); distribution unlimited. 


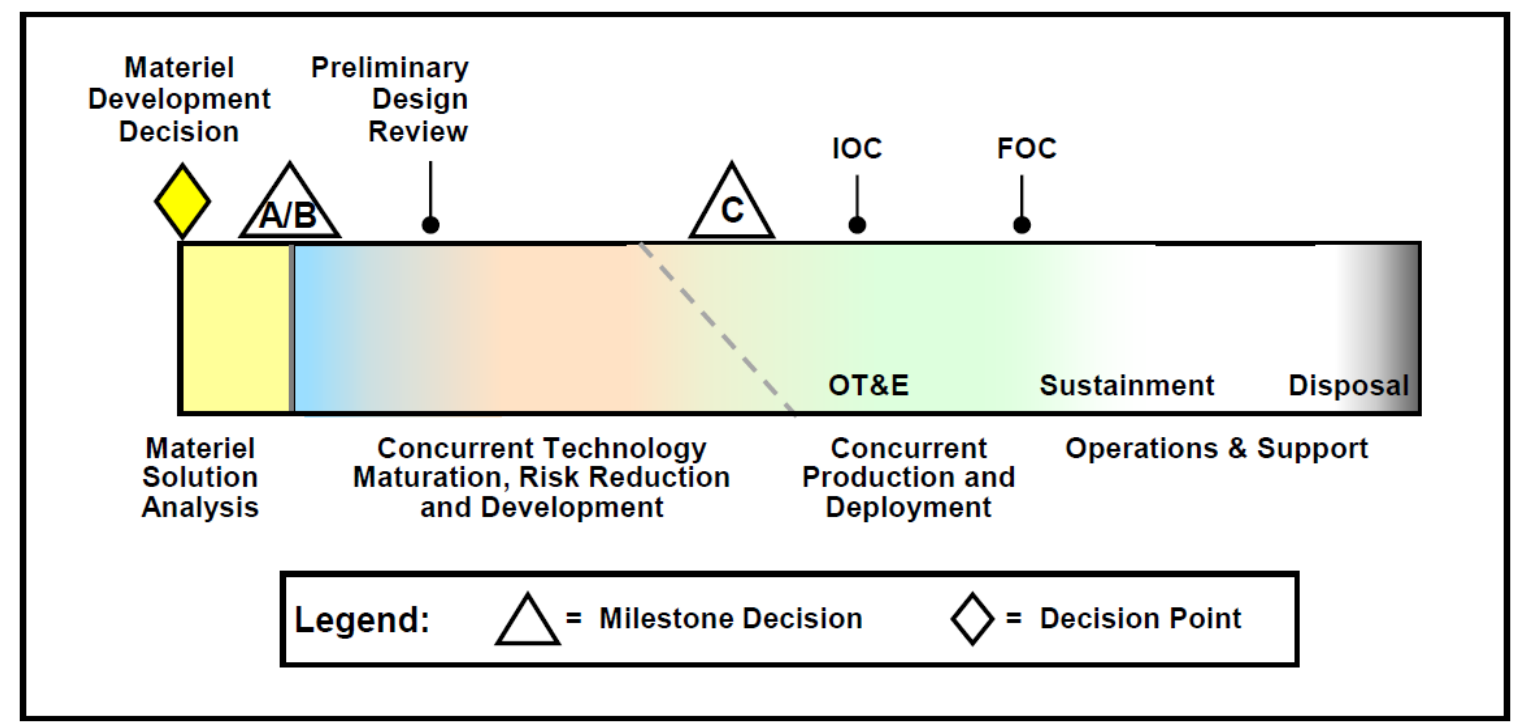

Figure 4: Defense Acquisition Process Sequence and Milestones for "Model 4 Accelerated Acquisition Program,” from Interim DODI 5000.02 (Nov 2013)

A key objective for the study task was to identify and evaluate methods or processes that might be used to accelerate maturation of manufacturing technologies and reduce program risk of implementation. The approach was to do this within the construct of the current MRL and MRA process. A brief review of the current MRL process is presented in the following section.

\subsection{Review of MRL and MRA Process}

Overview of Key MRL/MRA Elements: In the 1970's, NASA developed the concept of technology readiness levels, as an objective method to assess current readiness for specific applications. NASA subsequently published Definitions of the Technology Readiness Levels (TRLs) and associated gate criteria in the late 1980s [6] to guide technology development for future space systems. The TRL process, and the associated Technology Readiness Assessment process (TRA), are used extensively today by both government and industry - either directly or with some modifications. There are nine TRL levels, although various organizations, notably AFRL, have refined the gate criteria and developed comprehensive tools to help objectively assess TRL status. The current maturity of a technology is now often communicated by simply stating its TRL level. It should be noted that the TRL of a technology is evaluated in the context of a specific application, usually for a specific product or system.

One weakness in the TRL process (at least as commonly applied) was its lack of focus on manufacturing and production readiness for new technologies, especially for new materials or new manufacturing processes. This was recognized, and in 2001, the Joint Defense Manufacturing Technology Panel (JDMTP) established a working group to develop a set of Manufacturing Readiness Levels that were synchronized with corresponding TRL levels [7]. The initial set of definitions was first published as an appendix to the Technology Readiness Assessment Deskbook in 2003. 
Since then, a comprehensive website has been developed and maintained by JTMDP which contains many useful tools, guidelines, and references associated with the MRL process and associated Manufacturing Readiness Assessments (MRA), including reference links to the Technology Readiness Assessment Deskbook [8]. The gate definitions for MRLs, gate exit criteria, and relationship to TRLs and the Defense Acquisition System phases and milestones, are now well defined and are succinctly summarized in a single-page overview chart on the DoD MRL website [9].

The MRL assessment process has 10 defined readiness levels, as shown in Figure 2, above. The following comments and observations are made in the context of the present Study Task:

- MRL 1, 2 and 3 are essentially early planning gates, and are tied to efforts in the corresponding TRL process at the same gates.

- MRL 4 is a key gate that is tied to Acquisition Milestone A - the beginning of the Technology Development phase. At this gate, feasibility has been demonstrated in a lab environment, and key processes identified. The type of application is known, but specific system requirements may not yet be defined.

- MRL 5 and 6 gates require production of components in a relevant environment, and upon successful completion of the key MRL-6 gate, the manufacturing technology is considered mature enough to be included in the EMD phase which commences at Milestone B. At this point, specific target applications are well defined and system requirements are known.

- MRL 7 and 8 gates focus on process maturity and preparation for production, including process demonstrations, as well as the definition and validation of supply chain and quality requirements. The key gate of MRL-8 is associated with Milestone C, the start of the Production and Deployment phase. By this gate, pilot-line manufacturing has been successful, and the processes are believed ready for Low Rate Initial Production (LRIP).

- MRL 9 and 10 gates represent maturation of the manufacturing process(es) through low rate and finally into full-rate production capability, including process monitoring and statistical process control (at the Six Sigma or equivalent level).

- The MRL gate exit criteria are closely tied to the corresponding TRL gates; and require that the corresponding TRL gate has been passed.

- The MRL process is largely reactive to, rather than interactive with, the TRL process.

In addition to the well-defined gates, considerations, and exit criteria, nine "Manufacturing Threads” have been developed. These include the following:

- Technology and Industrial Base

- Design

- Cost and Funding

- Materials

- Process Capability and Control

- Quality Management

- Manufacturing Workforce

- Facilities 
- Manufacturing Management.

The considerations and exit criteria for MRL gates have been defined for each of the nine manufacturing threads listed above. This threaded construct provides the MRL assessment process with an organizing structure that is very useful for both industry and government. Questionnaires have been developed to assist Manufacturing Readiness Assessments, to identify and focus attention on activities in each thread that are necessary to achieve a desired MRL level, and to help objectively determine current MRL for subject technologies.

The recent cancellation of DODI 5000.02, and reissue as DODI Interim 5000.02, may significantly affect alignment of these well-defined MRL gates with the Defense Acquisition System key milestones. The conceptual program management models represented in the new "Interim" instruction will very likely drive actions to accelerate MRL maturation, especially for MRL levels of 5 and beyond.

Identification of Study Focal Areas within the MRL Process: The MRL and MRA processes are very comprehensive and well defined. They are increasingly used by industry and government, especially at the system level for major programs and weapons system acquisitions. In such applications, program management desires to assess the overall technology and production readiness for the entire system; thereby focusing on the manufacturing readiness assessment of the contractor's ability to produce the system or a major subsystem. However, there may be many individual technologies involved, each with different challenges and risks. This is especially a concern for so-called "critical technologies" - those that are included in the system configuration after Milestone B, which have not yet achieved TRL and MRL-6.

Also, there is certainly a desire to apply the MRL process to assess new and emerging technologies - perhaps even prior to a specific system application being clearly or fully defined. The Study Task is intended to identify opportunities and methods or tools that could generally accelerate maturity of new materials and manufacturing process technologies, and to better identify, reduce, and manage risks associated with such technologies, while working within the current MRL, MRA, and TRL processes.

There are many significant efforts currently underway in both government and industry that are relevant to this study task. Examples include many Integrated Computational Materials Engineering (ICME) projects aimed at materials and process modeling, the DARPA Open Manufacturing Initiative - with several performers engaged in developing methods for "rapid qualification" of materials and processes, and AFRL sponsorship of efforts to develop and exercise Verification and Validation methods for ICME.

With this context in mind, focus areas were identified for further assessment. In general, these included the following areas of consideration:

- Early risk identification and mitigation approaches

- Increased use of computational modeling for materials and processes (ICME), including empirically based modeling

- Verification and Validation methods for such modeling 
- Uncertainty Quantification and probabilistic assessments

- Feedback and updating methods for refining models based on early data

- Increased use of in-process monitoring and advanced inspection methods for process monitoring and control

- Definition and execution of critical experiments

These areas were generally related to the MRL gates and to the nine Manufacturing Threads previously cited, to ensure compatibility with the current, accepted process. It should be noted that in several cases, the recommended activities list associated with the manufacturing "threads" already contain some of the items identified for further assessment under this study task. For example, "Production modeling/simulation approaches identified" is contained in the Production Capability and Control thread, beginning with MRL-4. Also, "In-process and final inspections and statistical process control for prototype units" is contained in the Quality Management thread, beginning with MRL-5. Analyses of process variation, and associated process certifications to Six-Sigma or equivalent, are also listed activities, but they occur at high MRL levels. In general, the topics identified and evaluated under the study task are recommended as activities which begin sooner in the technology maturation process, and recommended activities are more comprehensive and integrated elements than are considered current practice. Also, references for established practices, guiding documents, or procedures are recommended to ensure appropriate application.

\subsection{Historical Examples}

Several prior materials/processing manufacturing efforts were identified and reviewed to provide background and historical reference to help clarify and focus ideas within this study. Given the background of the study participants, the examples focus on Aero-Propulsion manufacturing technologies; yet these examples undoubtedly share characteristics common to a broader selection of technologies important to DoD. Table 1 outlines some of the key issues of four manufacturing development efforts that encountered significant development challenges. The motivation for this table and the ensuing analysis is to identify some lessons learned to inform the identification of manufacturing risks earlier and with greater clarity.

Lessons Learned about Risks: These four development activities were undertaken in the 1970s and 1980s, prior to the emergence of formal, structured risk assessment processes that are now commonly exercised by both industrial and governmental organizations. Additionally, all four of the historical examples, listed in Table 1, represented revolutionary M\&P developments that departed significantly from the former mature manufacturing technologies that they were intended to replace. Because these new manufacturing technologies broke new ground, developers had only limited knowledge about what risks to expect and were thereby forced to iteratively react to problems as they emerged, with subsequent "fixes" only providing limited success.

Materials engineers have long understood that minimum material properties, such as LCF life, are usually govern by extreme microstructural features and particularly material defects. However, a large number of tests are needed to identify and understand extreme defects governing minimum properties (e.g., at the $-3 \sigma$ level); and as such significant development resources and time are required to gauge the full spectrum of defects, their individual behaviors, and design potential remediation approaches.

12

Distribution Statement A. Approved for public release (PA); distribution unlimited. 
Furthermore, defects revealed during initial laboratory development (using small scale equipment, clean lab environment, and highly skilled technicians) often are not the same as those produced within a production environment. Indeed, scale-up of As-HIP powder processing of rotor hardware, example 1 in Table 1, revealed more numerous ceramic defects - most likely due to longer atomization runs (melt-ceramic crucible interaction) and increased contamination from the factory environment (e.g., dirty air-lines, inadequate air handling/filtration, and equipment degradation owing to high machine duty-cycles and less frequent/less effective machine cleaning/maintenance). Indeed, the inadvertent inclusion of such contamination resulted in prior-particle boundary (PPB) decoration when these contaminants chemically reacted during hot-isostatic-pressing (HIP). Furthermore, the size of these PPB defects weren't constrained by the powder sieve size; and these subtle reactive PPB defects had low probability of detection via ultrasonic inspection because their volumetric presence was considerably lower than their impact on properties.

Table 1: Summary of prospective benefits and risks encountered for four historical manufacturing development $M \& P$ programs

\begin{tabular}{|c|c|c|c|}
\hline \# & $\begin{array}{c}\text { M\&P Manufacturing } \\
\text { Technology }\end{array}$ & Key Expected Benefits & Major Risk Issues \\
\hline 1 & $\begin{array}{l}\text { As-HIP Powder } \\
\text { Processing } \\
\text { (superalloy turbine rotor } \\
\text { components) }[10]\end{array}$ & $\begin{array}{l}\text { - Higher } \gamma^{\prime} \text { superalloys } \\
\text { - Reduced manufacturing cost } \\
\text { owing to avoidance of billet } \\
\text { working and forging } \\
\text { - Lower cost owing to expected } \\
\text { reduction in the number of } \\
\text { processing steps }\end{array}$ & $\begin{array}{l}\text { - Insufficient powder cleanliness } \\
\text { - Further powder contamination } \\
\text { during handling - including } \\
\text { reactive contaminants that } \\
\text { produced Prior Particle } \\
\text { Boundary (PPB) defects during } \\
\text { HIP. } \\
\text { - NDT inadequate to identify key } \\
\text { defects } \\
\text { - High inspection costs }\end{array}$ \\
\hline 2 & $\begin{array}{l}\text { Directionally Solidified } \\
\text { Superalloy Eutectics } \\
\text { (Turbine blades) }[11,12]\end{array}$ & $\begin{array}{l}\text { - Higher blade operating } \\
\text { temperature compared with } \\
\text { directionally solidified blades } \\
\text { - Improved longitudinal } \\
\text { strength and creep resistance }\end{array}$ & $\begin{array}{l}\text { - 3X higher cost compared to } \\
\text { DSX - owing largely to lower } \\
\text { growth rates and blades per } \\
\text { mold cluster } \\
\text { - Lower transverse properties } \\
\text { - Poor oxidation and HT } \\
\text { corrosion resistance } \\
\end{array}$ \\
\hline 3 & $\begin{array}{l}\text { Spray Forming } \\
\text { (Superalloy turbine rotor } \\
\text { components) [13] }\end{array}$ & $\begin{array}{l}\text { - Fine grain size \& increased } \\
\text { strength } \\
\text { - Avoidance of billet working } \\
\text { and forging operations } \\
\text { - Reduced manufacturing cost }\end{array}$ & $\begin{array}{l}\text { - Low ( }<30 \% \text { process yield) due } \\
\text { to overspray and particle } \\
\text { bounce } \\
\text { - Inadequate process control } \\
\text { - Porosity from gas entrapment \& } \\
\text { shrinkage }\end{array}$ \\
\hline 4 & $\begin{array}{l}\text { Continuous Fiber Ti } \\
\text { Metal Matrix Composites } \\
\text { (Aircraft panels and rotor } \\
\text { components) [14] }\end{array}$ & $\begin{array}{l}\text { - Reduced component weight } \\
\text { - Higher strength along fiber } \\
\text { direction }\end{array}$ & $\begin{array}{l}\text { - High material cost } \\
\text { - Low transverse LCF and FCG } \\
\text { - Lack of dimensional control } \\
\text { - Fiber diameter/stiffness limited } \\
\text { feasible component shapes } \\
\end{array}$ \\
\hline
\end{tabular}

All four historical examples, encountered unexpected cost challenges. For example, the cost reduction expected for As-HIP superalloy processing was lost due to the need to introduce 
sophisticated and costly quality control measures; powder inspection, finish part contour following ultrasonic inspection, and the adoption of low-cycle-fatigue testing as a specification requirement all added both cost and uncertainty. In contrast, the manufacture of directionally solidified eutectic blade was a technical success; but it ultimately succumbed to high processing costs. In this case developers understood that manufacture of eutectic turbine blades required control of the ratio of thermal gradient $(G)$ to the growth rate $(R)$ during solidification. To maintain a sufficiently high G/R ratio while achieving reasonable productivity meant that developers had to produce a high gradient within the furnace. Unfortunately, the number of blades that could be produced simultaneously in the directional solidification furnace had to be significantly reduced and yet the allowable growth rate was a mere 0.25 inches per hour. The resulting blade cost was greater than a factor of three compared to the baseline directionally solidified dendritic superalloy turbine blade it was meant to replace.

For all four of the historical development examples, the overarching risk, as alluded to at the outset, was the lack of up-front knowledge about these revolutionary development approaches. There was insufficient insight to predict or even imagine potential risk sources and inadequate plans at program inception to accelerate acquisition of required knowledge. It is tempting to wonder how modern risk assessment methods might have changed the trajectories and final results of these historical manufacturing developments. However, even today it can be extremely challenging to quickly identify, analyze, and resolve previously unknown and unexpected risks, particularly in new manufacturing domains.

\subsection{Early Risk Identification and Mitigation}

Plans for new Manufacturing Technology (MT) development, even those that pursue seemingly excellent opportunities too often have encountered major risks that disrupt the development process trajectory, lessen the benefit of the new MT, and/or cause program schedule and cost problems. As expressed within the MRL Deskbook:

"The purpose of an MRL-based assessment of manufacturing readiness is to analyze current conditions and to identify manufacturing risk in order to assist the program/project manager in creating a plan or options to reduce or remove risks."

Section 3.4 of this report presented four historical example MT development programs, each of which encountered unexpected risks that then led to either the suspension of further development and/or terminated implementation. Of course, most MT development programs don't encounter such extreme results. But most MT development programs do encounter risks that while not necessarily debilitating can disrupt MT development progress by requiring expanded and extended research, modifying or adding a process steps, or causing retrenchment from original program goals, payoff, and some implementation opportunities. These historical examples, though seemingly extreme, do provide a useful, cautionary perspective, mindset, and "meta lessons" that MT developers should consider to avoid or lessen similar risks in their programs.

Figure 5 depicts how risks can infect a manufacturing technology development program either through (1) inadequate MT process strategy \& design, and/or (2) deficient process and quality controls - as shown at the bottom and top of the figure, respectively. The two sets of boxes (outlined in red) highlight common risk sources, based on historical examples, though it is very unlikely that all will be encountered in a typical manufacturing technology development program. Obviously identification, assessment, and mitigation of risk should focus on those 
process steps that are new and thus less well known to the development team. Of course, the phrase "less well known to the development team" begs several questions that will be addressed below.

MT development program success is enhanced when developers proactively focus research and testing efforts to uncover technical and cost risks and then address and resolve them quickly. But unfortunately, some MT development teams instead unwittingly delay risk identification and instead focus, single mindedly, on activities intended to "prove" positive MT research claims and consequent projected benefits. As the historical examples have shown, failure to identify and then quickly resolve MT development risk can increase the risk of program failure.

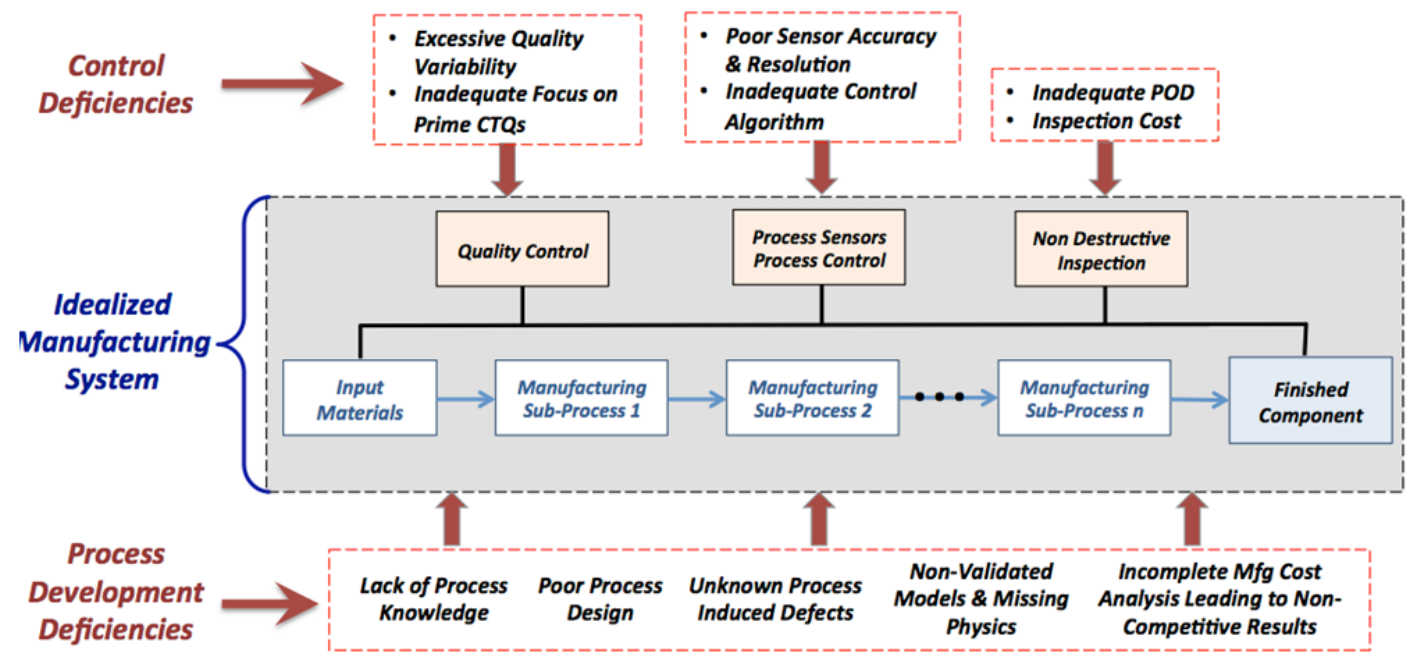

Figure 5: Diagram showing an idealized manufacturing process under development and the associated development and control deficiencies that can increase risk

Unfortunately, risk perception acuity for novel manufacturing technologies depends on the breadth of experience and the outlook (advocacy versus skepticism) of members of the Integrated Product Development Team (IPDT) - as well as the acceptance of contrarian viewpoints by the team and its leaders. Consider the three categories of MT process developments risk, listed below ${ }^{1}$ :

1. Known MT process risks that are understood,

2. Known MT process risks that are not understood, and

3. Unknown MT process risks that are not understood, even once discovered.

The first risk category addresses risks that are benign when addressed actively. Risks of this type should emerge during a formal risk assessment conducted by the team; and risk confirmation and subsequent mitigation should be straightforward because they are understood. Risks associated with the second category, like the first, should be identified as possible risks during a formal IPDT risk assessment. However, risk candidates in this second category will be more difficult to confidently confirm, quantify, or mitigate because understanding is lacking. Instead, if the

\footnotetext{
${ }^{1}$ A variant of former U.S. Secretary of Defense Donald Rumsfeld's well known quote regarding “ Unknown Unknowns,” or "Unk - Unks"
} 
team judges these risks to possibly have sufficient likelihood of occurrence and impact, the IPDT will need to undertake targeted research to fill the associated knowledge gap. The third risk category poses the greatest challenge to a MT development team, particularly regarding lurking risks that have low occurrence rates and moderate to high impact. These lurking risks, sometimes referred to as "black swans", cannot be identified using passive risk assessment and instead will emerge only during MT development experiments or trials for teams that fail to exercise active risk identification. If discovered during later stages of MT development, such risk events can have a debilitating effect on program success, cost, and/or schedule. Also, because this category of risk is also not understood, like the second category, research will be required to fully confirm, quantify, and mitigate these risks once they become known. Of course, if the risk does not appear until after prototype MT development has been completed, development will be disrupted further because research experiments will likely be more difficult to execute in a near-production environment.

There is one further point regarding the second and third categories of risk, alluded to earlier. The phrases "unknown MT process risks" and "are not understood" each beg the question of "who doesn't know" and "who doesn't understand". Of course the "who" is the MT development team; but other experts, outside the IPDT, may have direct knowledge or access to other resources, possibly from similar or related processes outside the purview of the MT development team. Also, independently, the IPDT can attempt to expand their knowledge of unfamiliar process step(s) by identifying analogous process step via patent, literature research, or ICME modeling. Consequently, identifying category 2 and 3 risks can be aided by the following strategies:

- Involving independent experts to augment the IPDT depth and breadth of knowledge;

- Accelerating MT experimental research, adapting and applying Integrated Computational Materials Science and Engineering (ICMSE), and implementing uncertainty quantification (UQ) for lesser known MT sub-processes; and

- Adding focus on increasing the robustness for sub-process that exhibit high variability during early MT experiments and trials.

The first strategy in the above list, involving outside experts, may appear to some as being counter-intuitive - after all, wouldn't an IPDT pursuing a state-of-the-art MT development include the necessary and pertinent expertise to successfully execute the MT development program? In many cases this may be true, but not necessarily for all MT development programs. Most technologies (including MT) advance via evolution; and often these advances are inspired and propelled by technology transfer from other processes and industries - directly, indirectly, or diffusely, via:

- $\quad$ Refining existing processes (via additional experimentation, modeling, control, process design refinements);

- Incorporating new sub-processes transferred from or inspired by external MT innovation in other, related industries; and/or

- Adopting a "new generic approach" developed in another field to advance the current manufacturing technology. 
If any of these three scenarios are applicable, the implication is that even when an MT development team is unexpectedly about to confront a "Known-Unk" or "Unk-Unk" risk:

- There may be outside experts that have already confronted these or similar risks;

- These outside experts may have knowledge about physical mechanisms, relevant models, NDE methods, QC testing procedures, uncertainty quantifications, or effective remediation approaches; and

- Independent outside experts (involved with predecessor technologies) can provide unbiased assessment of risk magnitude, and guidance about risk mitigation strategies and techniques as well recommendation regarding MT technical program modification.

The key bottom line is that an unknown risk lurking within a MT development program, in some instances, may be evident and understood with input from researchers and engineers outside the program; often gained through expert elicitation processes.

\subsection{Focus Areas Identified for Evaluation}

Based on the cumulative finding of the present study, we believe that the advance of manufacturing technology can be accelerated with greater confidence by implementing an integrated set of methods and practices, which were identified and evaluated under this Study Task. These included the following areas of consideration:

- Early risk identification and mitigation approaches

- Increased use of computational modeling for materials and processes (ICME), including empirically based modeling

- Verification and Validation methods for such modeling

- Uncertainty Quantification and probabilistic assessments

- Feedback and updating methods for refining models based on early data

- Increased use of in-process monitoring and advanced inspection methods for process monitoring and control

- Definition and execution of critical experiments

These topics were identified in this study as key factors to both accelerate the acquisition of essential knowledge, provide an earlier and more accurate identification of potential MT development risks, and engage a suite of activities intended to reduce risk and accelerate technology maturation. Each of these tactics/tools is described greater detail in the following sections.

3.6.1 Expert Elicitation. Expert elicitation (EE) is typically carried out using standard team processes, such as the Phenomena Identification and Ranking Technique (PIRT) and the Failure Modes, Effects, and Criticality Analysis (FMECA) ${ }^{2,3}$ by an independent team composed of experts from within and/or outside the companies and organizations engaged in the MT development effort.

\footnotetext{
2 The PIRT and FMECA processes will be described in greater detail in the Appendix to this report.

3 There are several other potentially useful methods including the Delphi Process.
} 
Based on the selected EE process and targeted MT process step(s), EE team membership should be selected such that their expertise spans the relevant disciplines and industrial processes associated with the MT development and output product. The span of expertise might include individuals with in-depth experience and knowledge in: manufacturing, materials \& processing technology, ICMSE modeling, quality control, and cost analysis, among others that are germane to the specific MT under development.

The two EE processes selected for focus, PIRT and FMECA, employ much different, yet complementary, lines of reasoning. Both EE techniques focus on MT process steps that are important, but less well known relative to process behavior and product characteristics. These two EE techniques are introduced in brief below with greater detail available in the appendix and via report references:

- PIRT is executed by first listing phenomena operative within targeted process steps. The EE team then judges and scores how important each phenomenon might be in influencing manufacturing system performance and product requirements, as well as the level of knowledge for each the phenomenon. Subsequently, "importance" and "knowledge" scores are combined and assessed to identify both the critical phenomena and MT research that should be considered to fill key knowledge gaps.

- FMECA starts by listing potential failure modes for each targeted process step. Much like for the PIRT process, the EE team then (1) lists potential effects caused by the failure and (2) judges and scores each potential failure mode relative to probability of failure, severity of the effect, and probability of detecting the failure or effect. After all potential failure modes are assessed and prioritized, the EE team recommends remedial actions.

Implementation of EE can have far reaching impact on MT development program success, particularly if it is initiated in the early stages of development. Much of the preceding discussion has focused or risk identification and assessment; however, EE benefits extend, either directly or indirectly, to the other systems engineering strategies and tools recommended by this study. All such down-stream benefits accrue through the enlightening effect of knowledge gained early enough to inform downstream decisions, which thereby should be improved, yielding greater process understanding. In a real sense, EE provide the following benefits beyond identifying key MT development risks, as shown in Figure 6:

Near Term (MRL 1 - 4):

- Identify manufacturing technology process gaps and help focus ensuing MT research;

- Guide ICMSE support teams to emphasize development of models that address high priority process steps and associated materials models; in turn, system engineering techniques can use these models to determine process parameter sensitivities, conduct analytical DOE analyses, and support uncertainty quantification calculations;

- Recommend critical material property measurements and experiments to better define process boundary conditions, process development trials, and important process parameters that should be measured and analyzed - particularly to support QC development efforts and aid uncertainty quantification assessments; and 
- Offer guidance on prospective NDE techniques and associated detection POD issues that may lie beyond the experience of the MT development team;

Later Term (MRL $4-7)$ :

- $\quad$ Review and critique MT development team efforts to verify and validate (V\&V) MT program ICMSE and uncertainty quantification (UQ) thrusts;

- Support manufacturing technology maturation and provide input to MT development planning and scale-up;

- $\quad$ Provide input to identify production QC and NDE needs and techniques; and;

- Provide guidance to help define and assess process control targets, strategies, and relevant sensor and control technologies.

Achieving these additional benefits will require that the MT IPDT determine where the EE team can provide benefit and then convene the EE team at critical MRL junctures.

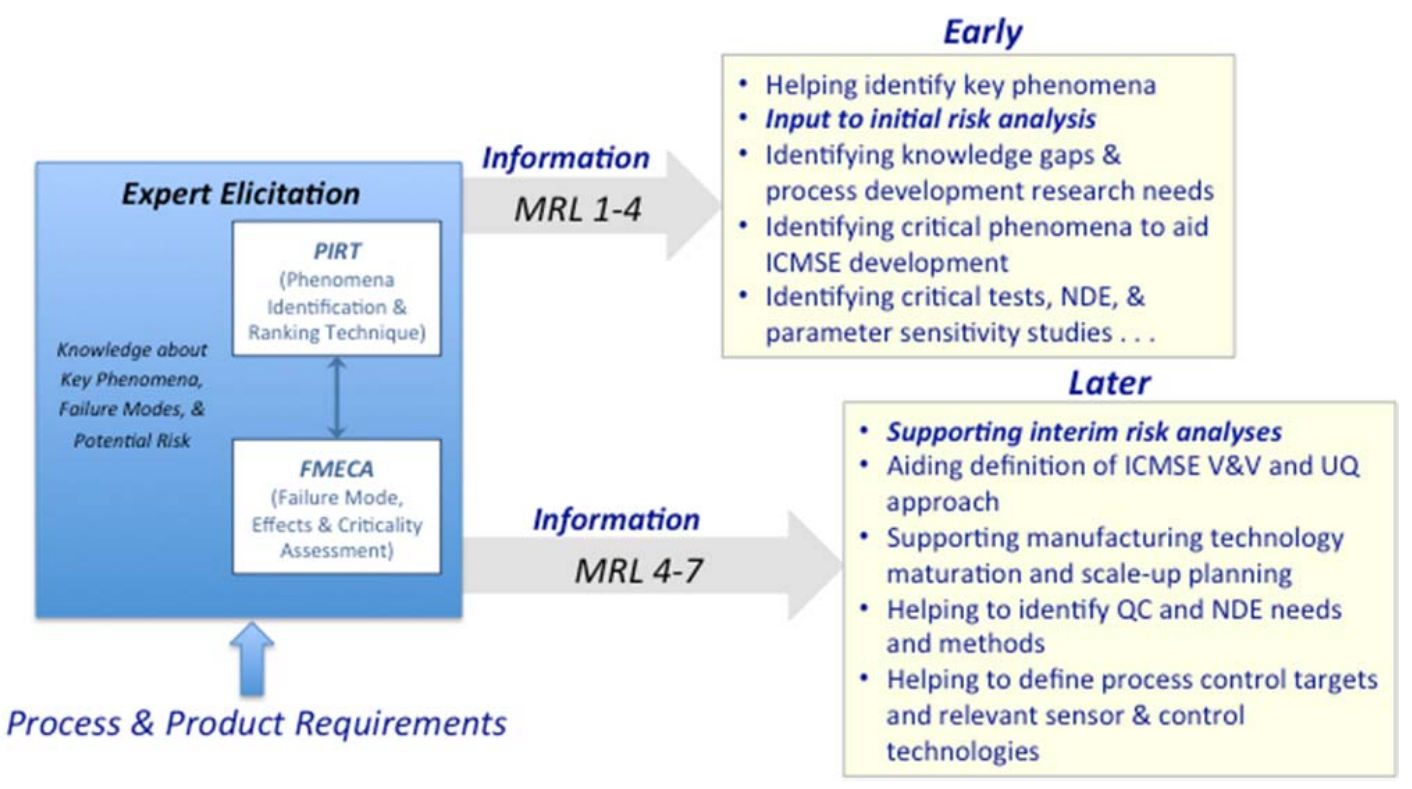

Figure 6: Outline of benefits that expert elicitation provides to an MT development effort

3.6.2 Computational Models for Materials, Manufacturing Technology, and Processes. Three areas identified for further evaluation are closely related. These are:

- Increased use of computational modeling for materials and processes (ICME), including empirically based modeling

- Verification and Validation methods for such modeling

- Uncertainty Quantification and probabilistic assessments

Increased use of computational modeling for materials and processes (ICME): The potential for ICME to provide significant benefit to materials and processing technology development has been cited by numerous studies at the national level. These include a landmark 2008 National Research Council study identifying ICME as a transformational discipline and essential future capability [15], a follow-on National Research Council study regarding importance of ICME for 
lightweighting technology application [16], and a TMS sponsored study regarding how to achieve pervasive ICME implementation [17]. It is also a primary focus and enabler for the White House's Office of Science and Technology Policy (OSTP) Materials Genome Initiative [18]. The means to align ICME with standard, gated development processes including TRL, MRL, IPD, and the DoD Defense Acquisition Guide milestones and process, have been described, and related to reduced time, cost and risk of new materials and manufacturing technology implementation.

ICME is now an integral part of many government agency and industrial development programs. There are now available a number of commercial codes and sources for various aspects of an ICME system. These include codes for thermodynamic-based materials analysis and predictions, various process models for casting, forging, and welding, and software capability to integrate various independent models with design, thermal, and structural analysis tools. Some successful applications of comprehensive ICME have been documented in the literature, but to date the broad implementation and integration of ICME with design, analysis, manufacturing, and quality disciplines has not been realized - at least not in general, standard practice. There are several initiatives underway that are either focused on accelerating ICME implementation, or are depending on ICME benefits to accelerate materials or manufacturing technology maturation. Two with special relevance to this study task are:

- AFRL sponsored Foundational Engineering Problem (FEP) initiatives for implementation of selected ICME applications. Of particular interest is the Metals Affordability Initiative (MAI) program, P\&W-8, for Incorporation of Residual Stresses in the Design of NickelBased Superalloy Structures.

- The DARPA sponsored Open Manufacturing initiative, specifically those programs focused on rapid qualification of additive manufacturing processes. DARPA Open Manufacturing is the first known program where ICME and related support activities, listed above, have been systematically incorporated as a means to accelerate manufacturing process qualification, and reduce risk of implementation of new materials and manufacturing technology.

In the ideal state, an ICME system will encompass comprehensive quantitative modeling of a material - whether metal alloy or composite - including its composition, processing, resulting microstructure, and finally the mechanical behavior and properties of the material relevant to the application of interest. While there are many challenges in the development of the integrated and linked models that comprise an ICME system, the capability has been demonstrated, and early results from the DARPA Open Manufacturing programs have been successful. The computational models that comprise an ICME system, and the supporting data used to generate the models, will facilitate much more direct integration of materials and manufacturing processes with the design, structural analysis, life prediction, and quality disciplines. Development and implementation of comprehensive, validated ICME methods and models will reduce dependence on lengthy, expensive test programs, reduce the number of development iterations, accelerate process optimization, enable tailoring to design and structural requirements, and guide informed process control and accelerated process qualification. 
Verification and Validation methods: For an ICME application to be successful and credible for decision making, rigorous verification and validation processes are essential. This is truly a critical requirement to ensure that program management, especially the chief engineers for the end product or application, and regulatory authorities, have confidence in the fidelity, maturity, and validation of model-based decisions.

The materials and processing discipline has been regarded less mature than other, more computationally focused engineering disciplines, in the area of rigorous $\mathrm{V} \& \mathrm{~V}$ for computational models. Rigorous verification and validation methods have been developed for other engineering disciplines - notably the 2006 ASME Guide for Verification and Validation for Computational Solid Mechanics [19]. This guide was the product of many years of continuous industry and agency efforts, and had the benefit of ASME committee focus to ensure a comprehensive and rigorous process. AFRL recognized the importance of $V \& V$ to future success of ICME, and has supported several efforts aimed at developing guidelines and a recommended best practice specifically for ICME V\&V and aerospace applications. Guidelines and a recommended best practice were developed which extensively referenced and incorporated the ASME V\&V Guide 10-2006. The ASME V\&V Guide was supplemented for specific ICME V\&V application: practitioner aides were developed in the form of checklists for $\mathrm{V} \& \mathrm{~V}$ planning and progress assessment, a Tool Maturity Level (TML) approach for assessing maturity of ICME methods and models, and a recommended approach for risk vs. consequence assessment related to use of ICME models for specific applications. [20]

It is important to note that the guidelines and the practitioner aides, including checklists and Tool Maturity Level assessment guide, are all aligned and integrated with established technology and system development gated processes - including TRL, MRL, IPD, and the Defense Acquisition Guidebook. This is important, because ICME and process model V\&V efforts must support the level of risk and consequence associated with specific applications. Alignment with the controlling, gated practices for technology and product development is critical to acceptance by program management, chief engineers, and responsible DoD or regulatory agencies. Recent updates to the guidelines and recommended best practice have been generated, and this version was approved by AFRL for public release, Distribution A, in January, 2014 [21]. The excel files with practitioner aides and recommended best practice summary has also been revised and approved for public release, Distribution A [22]. (Note: the site where these documents will reside for future reference purposes has not yet been determined - but they are available upon request from the authors).

Uncertainty Quantification: One critical element of ICME model development, V\&V, and process qualification, is Uncertainty Quantification (UQ). UQ represents assessment of model input parameters and their known or expected variation, followed by quantitative exercise of the computational model (or models) in a manner that permits assessment of the sensitivity and response of the model to the input parameters over the range of intended application. The result is a quantitative assessment of the uncertainty of the model and its sensitivity to parameters of interest. This is a complex but essential activity for guiding experimental efforts to support model development and validation, as well as to guide model refinements that may be needed to achieve desired or acceptable fidelity. The approach and key steps for UQ are described in the ASME V\&V Guide 10-2006 [19]. Recommendations for use of UQ and other probabilistic 
assessments are included in the Guidelines and Recommended Best Practice for ICME V\&V previously cited. These are dependent upon the assessment of Tool Maturity Level (TML), and of course are related directly to the intended ICME application

Both the AFRL FEP on Nickel Residual Stress, and the Open Manufacturing programs have clearly demonstrated that the necessary probabilistic tools and methods to support UQ are available and capable. In addition, the requisite expert practitioner skills are either available directly in the contract performer organizations, or are available in outside organizations such as Southwest Research Institute (SwRI) and universities. The results of UQ assessments are essential to guide model development, refinement, and validation efforts towards achieving acceleration of materials and manufacturing technology maturation, and reducing risk of implementation.

Recommendations Resulting From Study Task: Given that increased development and use of ICME for materials and manufacturing process models offers significant potential benefit for accelerated maturation of manufacturing technologies, when supported by the requisite V\&V and UQ supporting activities, the key questions are:

1. How much computational (or hybrid computational and empirical) modeling is appropriate, or optimal, and

2. How to align ICME model development and validation with the MRL and MRA processes?

The current Process Capability and Control thread lists "initial models developed, if applicable," as early as MRL-1, a high level manufacturing process flow chart is called for at MRL-2, "production modeling/simulation approaches identified" is included as an MRL 4 gate completion requirement. Additional descriptions of model/simulation progress follow under subsequent MRL gates. It appears that manufacturing variation is determined relatively late (MRL-7+), mostly by experimental measurement or demonstration of process output. It appears that the modeling and simulation efforts are largely targeted for eventual support of low rate or full production.

Recommendations from this study task are consistent with these current listings; but propose broader modeling and simulation expectations, close coupling with V\&V and UQ activities, and more integrated use of these models with design, materials, structures (analysis) and quality requirements. Equally important, it is believed that early development and continuous refinement of ICME and manufacturing process models, including assessment of variation, must be an integral part of accelerated maturation efforts. While these items may already appear in the various Manufacturing Threads, the Study Task recommends earlier application, and provides some added definition and detail.

The previously described alignment of ICME with current gated processes, including TRL, MRL, IPD, and Defense Acquisition Guidebook Milestone requirements (actually detailed in Interim DoDI 5000.02, issued November 2013) is regarded appropriate at this time. The ICME V\&V Guidelines and Recommended Best Practice [21, 22] is also believed appropriate, although the practitioner aides for Model and System Level Checklists, and the Tool Maturity

22

Distribution Statement A. Approved for public release (PA); distribution unlimited. 
Level (TML) assessment guide may need revision for specific application to manufacturing technology and consistency with the MRL process.

One important recommendation is that an ICME and manufacturing process modeling strategy be developed beginning very early - in the MRL 1 to 3 period. This may be initiated as a simple flow diagram, detailing expected processes and steps for a manufacturing technology under development. The simple flow diagram can be evolved as development proceeds, incorporating more detail, identifying where computational modeling is appropriate, and identifying key model inputs, required supporting data, key model outputs, and requirements for integration with other engineering disciplines and models. Utilization of the practitioner aides in the ICME V\&V Guidelines and Recommended Best Practice [22] provide assistance in terms of model and system level checklists, Tool Maturity Level assessment guidance, and use of tools such as PIRT for assessing key model parameters and hierarchy of sub-models. The initial assessment of UQ and development of a V\&V plan may occur later - in the MRL 4 to 6 period perhaps, and execution of the $V \& V$ plan and completion may occur even later.

The key recommendation is that a computational modeling plan and strategy be developed early, with expectation that it will be refined and detailed as technology development proceeds. Recommendations for when and how to do this within the current process are described under Section 4 of this report.

3.6.3 Feedback and Updating Processes. Experimental data is continuously generated as a normal part of Manufacturing Technology and supporting ICME developments. This experimental data is important for demonstration and quantification of new process capability and output, from basic material microstructure and properties to complex measures of capability and structural integrity, including relevant defect species. It is also essential to define process limits and controls, to validate sensitivity and effect of key process parameters, and ultimately to validate and support process qualification for intended applications. This data is also important for another purpose: a rigorous and systematic updating process to refine and improve ICME models and parameters, including their variation, which are deemed important to represent the materials and manufacturing processes of interest. Ideally, this would be a continuous or periodic closed loop process, and would continue beyond process qualification into the production phase of system acquisition. The updating process, whether based on the Bayesian inference method and function, or an alternative method, is essential to achieve a rapid maturation and validation of both the ICME models which may be employed, as well as key process parameters and controls that may be identified and used. This may differ substantially from legacy approaches, which often involve defining a process with empirical substantiation, establishing a "frozen process," followed sequentially by extensive experimental characterization of process output. In the not-uncommon event that some iteration in material, processing, or the end application becomes necessary - significant repetition of the experimental characterization program may be required. The intent, and a major benefit, of ICME-enabled technology development, with appropriate $\mathrm{V} \& \mathrm{~V}$, UQ, and systematic updating of models and data bases, is to minimize both the occurrence and impact of such development iterations.

The current Manufacturing Threads include mention of designed experiments (DFX) relatively late in the process - at MRL-6 and 7 under the Design thread, although use of statistical process 
control appears earlier at MRL-5 under the Quality Management thread. What is recommended as a result of this study task is systematic and disciplined use of updating and refinement methods for both the computational modeling efforts and the manufacturing processes themselves, beginning in the MRL $\sim 4$ to 5 time period and continuing thereafter. It is believed that such practices can accelerate maturation of new technologies, and accelerate achievement of statistical process control and realization of "six-sigma” process capability, before production commences at MRL-9 to 10.

3.6.4 In-Process Monitoring and Advanced Inspection Techniques. The advanced state of information technology for data acquisition and analysis, coupled with today's advanced sensor and inspection technologies, form the basis for another element for accelerating maturation and reducing risk of new materials and manufacturing process technology. In-process quality monitoring, and advanced inspection capability, offer independent methods to validate process output, ensure processes are operating within defined limits, and even provide potential for closed-loop control of key process parameters that was not previously possible. While such capability would be very beneficial as independent elements, they can be especially effective when coupled with ICME-enabled material and process modeling, and uncertainty quantification of key model parameters and outputs. The DARPA Open Manufacturing programs addressing Rapid Qualification have invested in advanced inspection methods and/or integrated in-process monitoring, as a means of achieving rapid qualification goals. These methods address a significant goal of the Open Manufacturing program for rapid qualification success: to develop significant understanding of process capability, performance, and limits that qualification for various applications can be greatly accelerated, and implementation risks greatly reduced.

The current manufacturing thread descriptions list identification of "in-process and final inspections" at MRL 4 and 5; and these are later associated with Key Process Characteristics (KPC's) at MRL-6, under the Quality Management thread. The use of Statistical Process Control is also contained in the Quality Management thread, beginning with prototype manufacturing at MRL-5. This Study Task advocates increased focus on in-process quality assurance that involves identification, direct measurement, and monitoring of key process control parameters. It is important to then integrate this accumulated information with ICME development to improve models and gain better assessment of uncertainty associated with modeling errors and process variation.

The Study Task recommends MT developers use in-process monitoring and advanced inspection techniques, beginning early in the MRL process. This approach can accelerate maturation of new technologies, achievement of (1) statistical process control, (2) accelerated realization of "sixsigma” process capability, and (3) add substantial confidence in new materials and manufacturing technologies. These results can be achieved largely by providing appropriate objective measures for key characteristics and parameters.

3.6.5 Definition and Execution of Critical Experiments. Comprehensive and often standardized experimental plans are almost always executed to support new material and manufacturing process development. These may be extensive and are intended to address many needs, ranging from basic properties to variation assessments and design or structures data requirements. When ICME models and methods are developed, additional experimental data to 
support model development, and eventually the requisite $\mathrm{V} \& \mathrm{~V}$ requirements, are also defined and executed. In addition, experimental validation is essential for progression from laboratory to pilot line to production processes. The specific recommendation made here, is that an integrated experimental strategy should be defined early in the technology development process, and that the experimental plan should specifically focus on definition and execution of "critical experiments," as a means of reducing risk and demonstrating capability for targeted conditions, geometries, and applications. "Critical experiments," in this context, are those experiments that can reproduce key conditions, test for required or critical attributes in a non-ambiguous manner, and provide objective, persuasive evidence that the manufacturing technology has matured to the level expected for a particular assessment gate or criteria. They may be part of a standard test protocol or plan, but are more likely to be specially designed tests to experimentally assess specific properties, capability, or attributes.

This integrated plan, in addition to including (or referencing) the well-established standard test requirements, should also ensure the following tenets are observed for the critical experiments:

- $\quad$ Progressive use of small to larger and finally full-scale or representative sizes be employed

- Progressive increase in configuration from simple to application-representative geometries at full scale sizes

- Definition and execution of critical experiments and associated success criteria at key MRL - typically gates 3 or 4, 6, and 7 .

- Integration of critical experiments with ICME V\&V requirements, other experimental plans including TRL required efforts, and with intended in-process quality monitoring and NDE developments.

The importance of carefully defining critical experiments and associated success criteria, and the integration of these with the overall experimental plan, resulted in recommendation of this as a specific activity.

3.6.6 Other Considerations. One related consideration is the likely need for design, materials, and manufacturing engineering skill development, specifically in the areas of ICME, process modeling, V\&V, UQ, and potentially other methods as described in this study task report. These skills are expanding, but are not yet broadly available in the workforce. Consequently, training and skill development in specific topics as described may be necessary for acceptance and implementation of the study task recommendations. Manufacturing management would likely also benefit from training and skill development in these areas, to better understand the potential benefits, challenges, and resources needed to support such activities. 


\subsection{RESULTS AND DISCUSSION}

\subsection{Concept of Systems Engineering for Manufacturing Development (SEMT) and General Alignment with MRL}

This study has found that the application of system engineering (SE) tools during the development of manufacturing technology can promote early identification of technical risks, accelerated development, and lead to improved, robust production processes that yield higher quality product. This report section offers a general approach for implementing these ideas within manufacturing.

\section{Background on SE implementation}

It is widely recognized that engineering has profited from the application of computational models, particularly when used along with integrated SE tools. Benefits have included accelerated development cycles, reduced reliance on component testing, and improved product performance, durability, and cost. Similarly, the materials community is now gaining traction in the development and application of models and SE that support material processing development and prediction of material properties. However, the transition from an experimental/testingcentric engineering workflow to one that incorporates both modeling and SE is evolutionary, with a rate of advance that depends on model maturation and the degree of SE validation. These earlier examples provide some lessons that are relevant to SE adoption within the manufacturing development community:

- The application of modeling and SE should not be prescriptive; instead the IPDT should plan modeling/SE efforts to meet program needs and projected benefits. A prescriptive approach for model/SE implementation is neither recommended nor will it likely be successful. Development programs vary in how they can apply and benefit from modeling and SE, depending on: (1) maturity of the baseline technology, (2) depth of process knowledge, (3) quantity/quality of relevant process data, (4) availability of modeling tools, (5) criticality of associated product requirements, and (6) available funding and schedule - among others.

- Development teams should identify the critical elements and mechanisms that require physics-based modeling using risk, PIRT, and/or FMECA analyses to guide the team's selection. These same methods can be applied to identify key data gaps, identification of critical MT experiments, and important SE applications during the MT development process

- Successful application of SE requires a judicious balance between knowledge gained from experimental data and physics-based modeling. Successful implementation of modeling and SE tools depends strongly upon experimental and test data to generate data-driven models, provide model inputs, quantify constituent properties, establish model boundary conditions, calibrate a model, quantify uncertainty, or validate a model or engineering analysis.

Successful adoption of modeling and SE depends on trust; verification and validation are paramount. Changing or enhancing an engineering process - whether in design, materials, or manufacturing - must overcome hurdles (e.g., cultural resistance, transition risks \& costs, and engineer training). Management and engineers must trust that SE implementation change leads 
to reliable process and product improvement; and achieving this trust is built upon rigorous and complete verification and validation of individual models and the complete SE-ICME system.

Effort in Task 3 focused on refinement and finalization of recommended topics and activities that could accelerate maturation and reduce risk for new manufacturing technologies (MT). One key challenge, of course, is how to facilitate implementation? It was believed essential that such recommended activities be closely aligned with the current MRL/MRA process, including the approach to sequencing and gate criteria. It was also believed essential that the recommended activities be integrated into a cohesive package, rather than treated as independent, stand-alone topics, in order to realize maximum system benefit. The result was to define and propose an additional "Manufacturing Thread," with sub-threads that contain the recommended topics and activities identified in the Study Task. The proposed Systems Engineering for Manufacturing Technology (SEMT) sub-threads are illustrated in Table 2, below, in relation to the current nine (9) manufacturing threads, and to the consolidated listing of the MRL gates.

Table 2: SEMT Focus areas consolidated as Sub-threads in relation to MRL and Current Manufacturing Threads

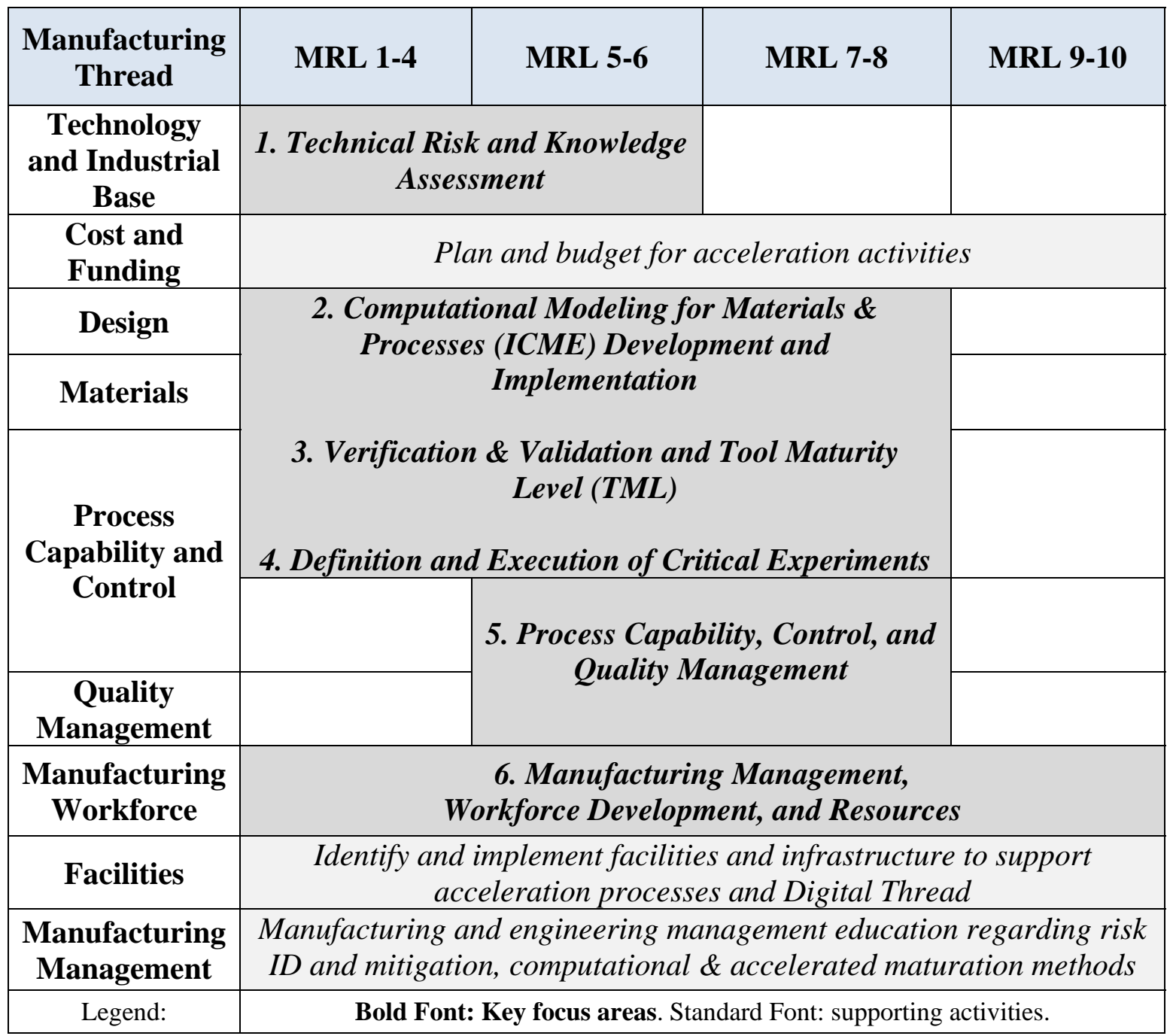

Distribution Statement A. Approved for public release (PA); distribution unlimited. 
Figure 7, below, is an attempt to illustrate these methods and tools as an integrated approach to accelerate maturation of new materials and manufacturing technologies. The highlighted boxes indicate recommended changes or additions to legacy practices. The Expert Elicitation box represents the Early Risk Identification and Mitigation topic, and as shown, is intended to be initiated early - preferably by MRL-2, but certainly before completion of the MRL 3 to 4 gates. There are several established methods that can be used, including PIRT and FMECA, which are regarded especially useful and were described earlier in this report. The selection of appropriate method and level of detail will be dependent on the application - including the fidelity of model or process definition at the time. Methods such as PIRT could certainly be applied very early even at MRL gates 1 and 2, and then more rigorous, detailed exercises conducted as the applications and requirements of the technology become better defined. Also shown early in the process are activities to define a Modeling Strategy and also a corresponding Experimental Strategy - especially regarding definition of critical experiments. These strategies would be expected to change and mature over time, of course, with more detail and fidelity developed as a technology development program progresses.

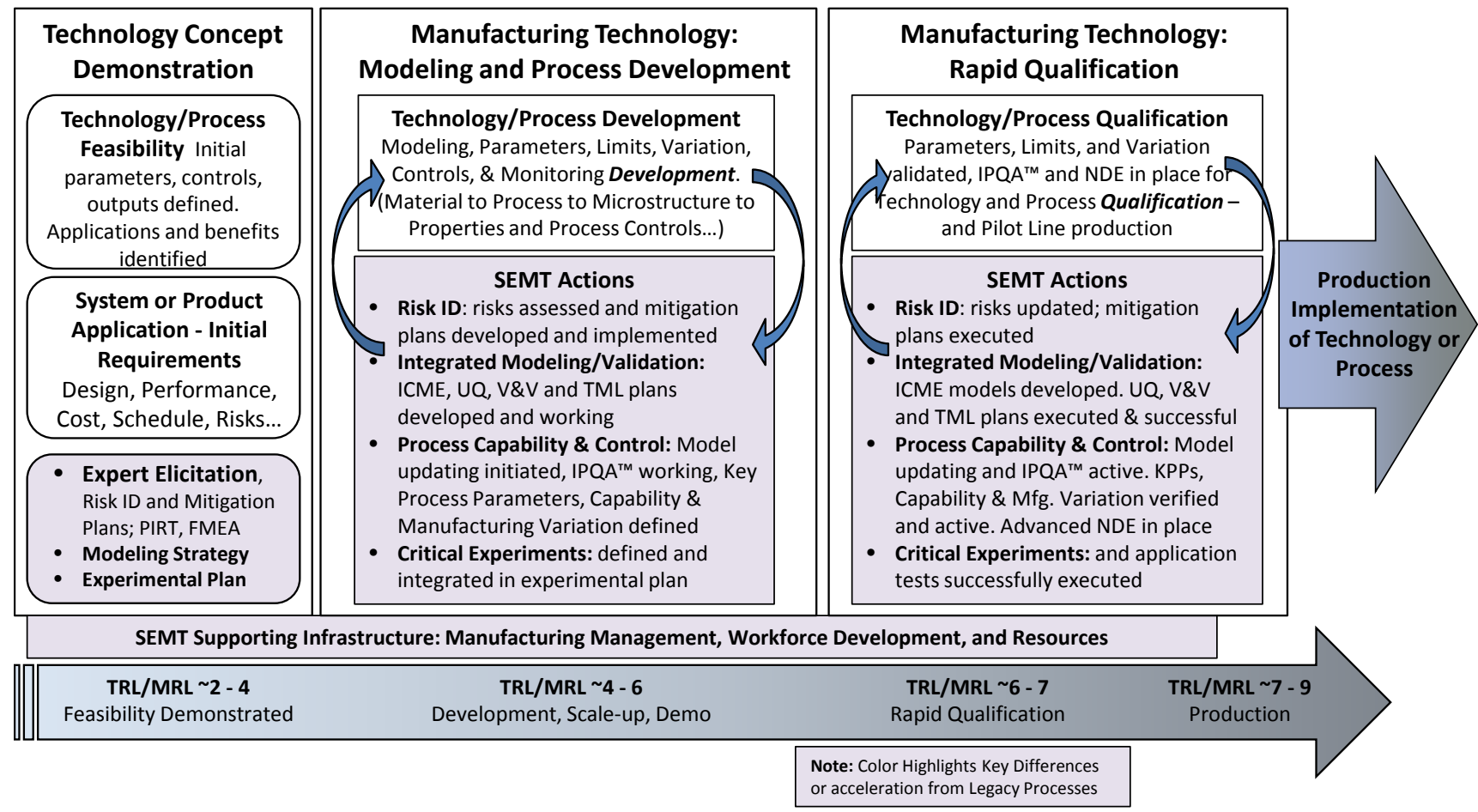

\section{Figure 7: Concept Illustration of Proposed SEMT Activities in Current MRL Process}

Moving to the right in Figure 7, the SEMT actions are focused on supporting technology development, and the expectation is that an iterative and integrated set of activities as defined under the SEMT thread would support technology development - in the range of TRL/MRL-4 to 6, but then continue, and support technology qualification and validation in the range of MRL-6 to 7, and beyond. Efforts on ICME V\&V shift from planning to execution as MRL status progresses from MRL-4 to 6 out to MRL -6 to 7 and beyond. Also, as the technology is matured, and collected data increases, model updating methods can be implemented, continuous in- 
process quality assurance and monitoring data can be generated and analyzed, and statistically (even probabilistically) relevant data basis and process limits established. Figure 7 is intended to show the close integration of modeling efforts with manufacturing process development, and later, process and technology qualification. As illustrated, it should be an iterative and integrated relationship.

\subsection{Proposed Systems Engineering for Manufacturing Technology (SEMT)}

Implementation of Systems Engineering (SE) to support manufacturing development ideally should meld seamlessly with existing MT development processes. The format and context of SE insertion should be designed so that it is familiar, concise, and easily understood by MT IPDT members - yet, also supported by more detailed documentation, particularly during early stages of deployment.

The topic areas that were identified and evaluated as described in Section 3.6 of this report were reviewed and consolidated into related activities. "Expert Elicitation, "as described in Section 3.6.1, along with risk assessment and mitigation methods and non-advocate review processes, were included in a single defined "sub-thread:" "Technical Risk \& Knowledge Assessment." Topics that were identified and evaluated in Section 3.6.2 included computational modeling, ICME V\&V, uncertainty quantification, and probabilistic methods. These closely related topics were divided into two sub-threads: "ICME Development and Implementation," and "Verification \& Validation and Tool Maturity Level." The topic described as critical MT experiments, and development of an overall experimental strategy, as described in Section 3.6.5, was included as a single sub-thread, "Definition and Execution of Critical Experiments." The topics identified and evaluated as "in-process monitoring and advanced inspection techniques, from Section 3.6.4, and "feedback and updating processes, from Section 3.6.3, were combined into a single sub-thread: "Process Capability, Control, and Quality Management." Finally, what was described in Section 3.6.6 as "other considerations," was developed into a single sub-thread: Manufacturing Management, Workforce Development, and Resources."

This grouping of recommended activities into defined "sub-threads" was based on the expected relationship of the activities to one another, as well as how they align with the current MRL process and associated nine Manufacturing Threads. The definition of these six SEMT subthreads, and the way various activities are included and grouped, could of course be changed.

The natural insertion point/vehicle, that addresses these criteria, is the MRL Threaded Matrix. This study proposes the creation of one additional MRL thread, entitled "System Engineering for Manufacturing Technology (SEMT)," as shown in Figure 8. This new SE thread has six subthreads, shown in Figure 8, covering the full spectrum of SE activities and MRL gates from knowledge assessment, to ICME model and data development, to application of SE analysis, and associated managerial, workforce, and facility issues. 


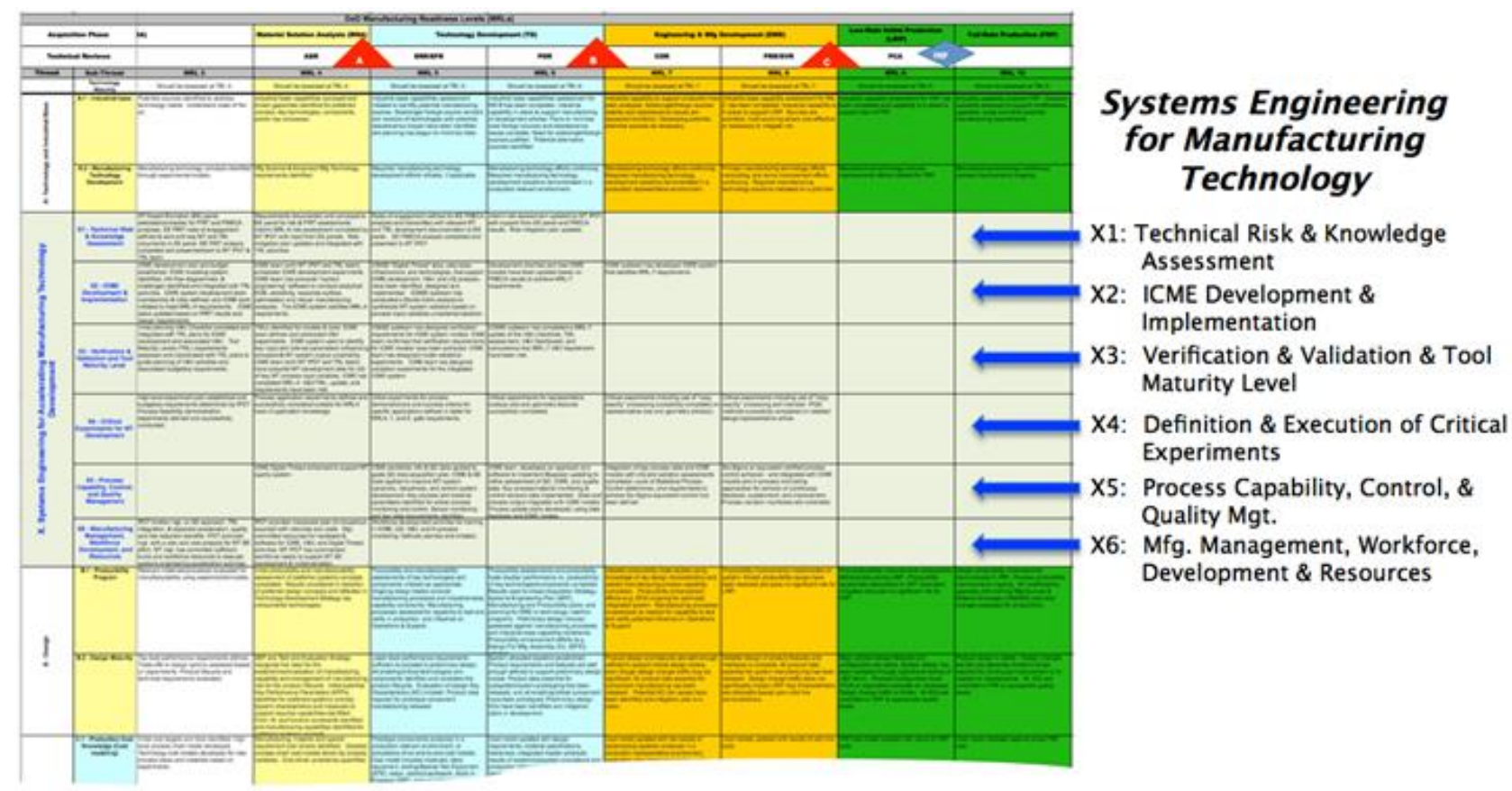

Figure 8: Schematic illustration shows the proposed SEMT thread and its six Sub-threads (light green color) inserted within the MRL threaded matrix

The content of the six SEMT sub-threads are listed and ordered by MRL level within tables presented in each of the next six subsections of this report; supplemented by brief introductory comments. Because there are numerous dependencies among activities from different subthreads, a three-step process was used: (1) activities were listed for each sub-thread; (2) each listing was ordered to yield a logical activity sequence; and finally (3) MRL levels were assigned to align the sub-threads with each other and most importantly with program activities and requirements of the overall MT program.

4.2.1 Sub-thread 1: Technical Risk and Knowledge Assessment. Manufacturing risk is an important focus of the MRL process; as expressed within the MRL Deskbook: "The purpose of an MRL-based assessment of manufacturing readiness is to analyze current conditions and to identify manufacturing risk in order to assist the program/project manager in creating a plan or options to reduce or remove risks.” And while the current threaded MRL Matrix contains risk assessment activities, a Systems Engineering (SE) sub-thread, "Technical Risk and Knowledge Assessment” is proposed to: (1) highlight the challenges of risk identification during development of novel MT; (2) emphasize the importance of addressing risk assessment and mitigation earlier in development; and (3) recognize the beneficial and symbiotic interplay between risk analysis, expert elicitation, and SE tools for acquiring MT process knowledge more quickly and identifying development risk earlier. "Expert Elicitation, "as described in Section 3.6.1, along with risk assessment and mitigation methods and non-advocate review processes, were included in a single defined "sub-thread:" "Technical Risk \& Knowledge Assessment.”

Intent and Rationale:

- $\quad$ Perform progressive risk assessments within the IPDT

Distribution Statement A. Approved for public release (PA); distribution unlimited. 
- Exercise expert elicitation (EE) to:

- Assess key assumptions within the development strategy

- Identify key knowledge gaps that must be addressed early

- Weave expert elicitation into the MRL \& MRA processes

- Build complementary efforts to do DOEs, models, UQ methods to fill knowledge gaps

- Engage independent experts to probe scale-up and technology transfer risks along the progression from laboratory to production implementation.

Attributes and Potential Benefits:

- Identification of risk drivers and pitfalls earlier

- Use of expert elicitation processes such as PIRT and FMECA

- Early \& more accurate program development decision-making.

Almost all MT development programs do encounter risks, which while not necessarily debilitating, can disrupt MT development progress, by requiring expanded and extended research, modifying or adding a process step(s), or causing retrenchment from original program goals, payoff, and reduction of implementation opportunities. MT development programs succeed when developers proactively include research and testing efforts to uncover and resolve risks quickly; instead of focusing solely on research directed to prove MT benefits. Indeed, the ability of an MT IPDT to perceive risk depends on the knowledge and breadth of experience of the IPDT team members. Accelerating identification of "low probability of occurrence" risks is aided by the following strategies:

- Involving independent experts to augment the IPDT depth and breadth of knowledge;

- Accelerating MT experimental research, adapting and applying Integrated Computational Materials Science and Engineering (ICMSE), and implementing uncertainty quantification (UQ) for lesser known MT sub-processes; and

- Adding focus on increasing the robustness for sub-process(es) that exhibit high variability during early MT experiments and trials.

This sub-thread focuses on Expert Elicitation, which entails methods to expand the knowledge and to sharpen the technical insight of the team assessing the MT development. Expert elicitation (EE) is typically carried out using standard team processes, such as the Phenomena Identification and Ranking Technique (PIRT) and the Failure Modes, Effects, and Criticality Analysis (FEMCA) by an independent team composed of experts from within or outside the companies engaged in the MT development effort; see further details in the appendix.

Implementation of EE can have far reaching impact on MT development program success, particularly if it is initiated in the early stages of development. EE benefits extend, either directly or indirectly, to the other systems engineering strategies and tools and these benefits accrue through the enlightening effect of knowledge gained to inform downstream decisions.

Development of manufacturing technology is highly dependent on both engineering knowledge and judgment. Mathematical and data-driven models as well systems engineering tools can have a powerful impact on the rate of development progress and success - but only after manufacturing engineers have defined the MT project and requirements, identified the manufacturing process, uncovered critical process mechanisms and risks, and selected the modeling, critical data, and experimentation that collectively can accelerate and enhance MT development.

Distribution Statement A. Approved for public release (PA); distribution unlimited. 
The sub-thread addresses the application of engineering knowledge to:

- Identify, assess program risk and define potential mitigation activities,

- Identify MT knowledge gaps and define engineering analysis and experimentation to fill the gaps, and

- Isolate potential process failure mechanisms, and provide remedial and abatement countermeasures.

For this SEMT sub-thread, recommended activities and their alignment with MRL gates are presented in Table 3, below.

Table 3: Technical Risk and Knowledge Assessment Sub-thread and MRL Alignment

\begin{tabular}{|c|c|c|}
\hline \# & $\begin{array}{l}\text { MRL } \\
\text { Level }\end{array}$ & Risk and Knowledge Assessment \\
\hline 1 & 2 & $\begin{array}{l}\text { Initial risk assessment completed by Manufacturing Technology IPDT. } \\
\text { Assessment of TRL plan (the TDP) completed. Integration of MRL and TRL } \\
\text { activities planned. }\end{array}$ \\
\hline 2 & 3 & $\begin{array}{l}\text { Manufacturing technology (MT) Expert Elicitation panel selected and } \\
\text { engaged for subsequent PIRT and FMECA analyses. }\end{array}$ \\
\hline 3 & 3 & $\begin{array}{l}\text { Rules of engagement defined for Expert Elicitation PIRT analysis and } \\
\text { transmitted along with relevant MT and TRL documentation to Expert } \\
\text { Elicitation panel. }\end{array}$ \\
\hline 4 & 3 & $\begin{array}{l}\text { Expert Elicitation PIRT analysis completed and presented to MT IPDT. } \\
\text { Results communicated to TRL team. }\end{array}$ \\
\hline 5 & 4 & $\begin{array}{l}\text { Component and Material requirements have been documented and } \\
\text { conveyed to Expert Elicitation panel for subsequent risk and knowledge } \\
\text { assessments. }\end{array}$ \\
\hline 6 & 4 & $\begin{array}{l}\text { Interim MRL-4 risk assessment completed by Manufacturing Technology } \\
\text { IPDT with support from Expert Elicitation panel and PIRT results. Risk } \\
\text { mitigation plan updated and integrated with TRL activities. }\end{array}$ \\
\hline 7 & 5 & $\begin{array}{l}\text { Rules of engagement defined for Expert Elicitation FMECA analysis and } \\
\text { transmitted along with relevant MT and TRL development documentation to } \\
\text { Expert Elicitation panel. }\end{array}$ \\
\hline 8 & 5 & Expert Elicitation FMECA analysis completed and presented to MT IPDT. \\
\hline 9 & 6 & $\begin{array}{l}\text { Interim risk assessment updated by MT IPDT with support from Expert } \\
\text { Elicitation panel and FMECA results. Risk mitigation plan updated. }\end{array}$ \\
\hline
\end{tabular}

The tools involve standard risk analysis and expert elicitation (EE) methods as exercised by the MT IDPT or an independent panel composed of external domain experts from government labs, academia, or industry. In addition, the IPDT may benefit by replacing critical EE exercises with a formal Non-Advocate Review (NAR).

4.2.2 Sub-thread 2: Integrated Computational Materials Engineering (ICME). A fully mature ICME system includes (1) mathematical models covering physically-based and dataderived knowledge; (2) databases for material properties, physical constants, \& experimental 
data; (3) SE tools for DOE, sensitivity, optimization, and robust design analysis. Collectively these represent the sources of domain knowledge; whereas the third provides the means and methods to exercise this knowledge to improve manufacturing processes. ICME and computational modeling in general were identified and evaluated in Section 3.6.2 and are now included in the $2^{\text {nd }}$ sub-thread: "ICME Development and Implementation."

\section{Intent and Rationale:}

- Application of ICME models that incorporate material science mechanisms and associated process physics can significantly accelerate knowledge acquisition:

- Identify and interpret process anomalies earlier

- Improve manufacturing processes more quickly

- Integrate ICME and Digital Thread for better development analysis

- Apply System Engineering tools to reduce development iterations leading to more robust controlled manufacturing processes

Attributes and Potential Benefits:

- Organized approach that yields component improvement more quickly, at lower cost, and lower risk

- $\quad$ Promote reuse of models \& knowledge for down-stream improvement and developments

- Reduce risk of development iterations, and facilitate faster, less costly response to any system or design iterations

Ideally, an ICME system will encompass comprehensive quantitative modeling of a material whether metal alloy or composite - including its composition, processing, resulting microstructure, and finally the mechanical behavior and properties of the material relevant to the application of interest. While there are many challenges in the development of the integrated and linked models that comprise an ICME system, the capability has been demonstrated in many programs, and utilization of ICME is increasing rapidly. The computational models that comprise an ICME system, and the supporting data used to generate the models, will facilitate much more direct integration of materials and manufacturing processes with the design, structural analysis, life prediction, and quality disciplines. Development and implementation of comprehensive, validated ICME methods and models will reduce dependence on lengthy, expensive test programs, reduce the number of development iterations, accelerate process optimization, enable tailoring to design and structural requirements, and guide informed process control and accelerated process qualification.

For this SEMT sub-thread, recommended activities and their alignment with MRL gates are presented in Table 4, below. 
Table 4: ICME Sub-thread and MRL Alignment

\begin{tabular}{|c|c|c|}
\hline \# & $\begin{array}{l}\text { MRL } \\
\text { Level }\end{array}$ & Integrated Computational Materials Engineering (ICME) \\
\hline 1 & 2 & $\begin{array}{l}\text { Notional ICME system outlined and integrated with TRL ICME plan, including } \\
\text { expected key models and tools. Significant modeling gaps identified. Initial } \\
\text { ICME modeling and V\&V strategy defined. }\end{array}$ \\
\hline 2 & 3 & $\begin{array}{l}\text { High-level ICME development plan established and budgetary requirements } \\
\text { determined by IPDT. }\end{array}$ \\
\hline 3 & 3 & $\begin{array}{l}\text { Initial ICME modeling system identified, diagrammed with informational flows, } \\
\text { and technical challenges identified and integrated with TRL activities. }\end{array}$ \\
\hline 4 & 3 & $\begin{array}{l}\text { MT IPDT has assembled ICME system development team; and initiated } \\
\text { model development to achieve MRL-4 requirements. }\end{array}$ \\
\hline 5 & 3 & $\begin{array}{l}\text { Development priorities for new ICME models established based on PIRT } \\
\text { results and material/component requirements. }\end{array}$ \\
\hline 6 & 4 & $\begin{array}{l}\text { ICME team has coordinated with MT IPDT and TRL team to schedule MT } \\
\text { experiments that support ICME development. }\end{array}$ \\
\hline 7 & 4 & $\begin{array}{l}\text { ICME has identified and procured "system engineering" software (e.g., } \\
\text { Phoenix's Model Center or iSIGHT) to conduct analytical DOE, sensitivity, } \\
\text { response surface, optimization and robust manufacturing analyses. }\end{array}$ \\
\hline 8 & 4 & ICME team has developed ICME system that satisfies MRL-4 requirements. \\
\hline 9 & 5 & $\begin{array}{l}\text { ICMSE "Digital Thread" data, data base, infrastructure, and technologies, that } \\
\text { support ICME development, V\&V, and UQ analysis, have been identified, } \\
\text { designed and implemented. }\end{array}$ \\
\hline 10 & 5 & $\begin{array}{l}\text { ICSME team has conducted a Monte Carlo analysis to synthesize MT system } \\
\text { variation based on process input variables uncertainty/variation. }\end{array}$ \\
\hline 11 & 6 & $\begin{array}{l}\text { Development priorities and new ICME models have been updated based on } \\
\text { FMECA results to achieve MRL-7 requirements. }\end{array}$ \\
\hline 12 & 7 & ICME team has developed ICME system that satisfies MRL-7 requirements. \\
\hline
\end{tabular}

4.2.3 Sub-thread 3: Verification and Validation and Tool Maturity Level. Verification, validation and Tool Maturity Level (TML) assessment is critical for building confidence that an SEMT analysis has acceptable accuracy and uncertainty bounds. Although the activities for this V\&V/TML sub-thread are intimately linked to the second sub-thread on ICME, it has been allocated a separate sub-thread for clarity, to emphasize its importance, and to acknowledge that V\&V exercises requires independent data to validate both ICME model and system level predictions. Also included in this sub-thread is the topic of uncertainty quantification (UQ), as an essential component of ICME V\&V assessment. In addition, UQ is an essential part of assessing manufacturing variation - especially process variation - which is addressed in another sub-thread. These topics were identified and evaluated as described in Section 3.6.2, and a number of references were provided in that section.

Intent and Rationale:

- $\quad$ Successful \& trustworthy application of ICME and Systems Engineering depends on:

- Verifying that ICME models are solving equations correctly

Distribution Statement A. Approved for public release (PA); distribution unlimited. 
- Validating that ICME modeling results match the real-world application

- Quantifying uncertainty (UQ) for both program data and simulation results

- Ensuring that current modeling maturity meets application requirements

- Follow the V\&V and Tool Maturity guidelines developed by AFRL \& MAI, or equivalent process

\section{Attributes and Potential Benefits:}

- Builds trust in ICME \& Systems Engineering within the IPDT and with the customer

- Ensures V\&V activity is appropriate and sufficient for the system or product application

- Provides quantitative understanding of uncertainty that promotes improved development decision making.

Recommended activities and their alignment with MRL gates are presented in Table 5, below.

\section{Table 5: V\&V and TML Sub-thread and MRL Alignment}

\begin{tabular}{|c|c|c|}
\hline \# & $\begin{array}{l}\text { MRL } \\
\text { Level }\end{array}$ & Verification \& Validation and Tool Maturity Level \\
\hline 1 & 3 & $\begin{array}{l}\text { Initial planning V\&V Checklist completed and integrated with TRL plans for } \\
\text { ICME development and associated V\&V. }\end{array}$ \\
\hline 2 & 3 & $\begin{array}{l}\text { Tool Maturity Levels (TML) requirements assessed and coordinated with TRL } \\
\text { plans to guide planning of } V \& V \text { activities and associated budgetary } \\
\text { requirements. }\end{array}$ \\
\hline 3 & 4 & ICME team has identified initial TMLs for individual models and tools. \\
\hline 4 & 4 & $\begin{array}{l}\text { ICME team has coordinated with MT IPDT and TRL team to define and } \\
\text { schedule MT experiments that support ICME V\&V. }\end{array}$ \\
\hline 5 & 4 & $\begin{array}{l}\text { ICME team has applied initial ICME system to identify the most influential } \\
\text { input and internal parameters governing ICME simulation and MT system } \\
\text { output uncertainty. }\end{array}$ \\
\hline 6 & 4 & $\begin{array}{l}\text { ICME team has coordinated with MT IPDT and TRL team to acquire MT } \\
\text { development data to quantify uncertainty for highly sensitive MT process input } \\
\text { variables. }\end{array}$ \\
\hline 7 & 4 & $\begin{array}{l}\text { ICME has completed a MRL- } 4 \text { update of the } V \& V \text { checklists, TML } \\
\text { assessment, V\&V Dashboard and concurrence that MRL- } 4 \text { V\&V requirement } \\
\text { have been met. }\end{array}$ \\
\hline 8 & 5 & $\begin{array}{l}\text { ICMSE team has designed verification requirements for individual models of } \\
\text { the ICME system. }\end{array}$ \\
\hline 9 & 5 & $\begin{array}{l}\text { ICME team has confirmed that verification requirements of all models in the } \\
\text { ICME system have been achieved. }\end{array}$ \\
\hline 10 & 5 & $\begin{array}{l}\text { ICME team has designed validation experiments to validate individual models } \\
\text { in the ICME system. }\end{array}$ \\
\hline 11 & 5 & $\begin{array}{l}\text { ICME team has designed validation experiments to validate the fully } \\
\text { integrated ICME system. }\end{array}$ \\
\hline 12 & 6 & $\begin{array}{l}\text { ICSME team has completed a MRL- } 7 \text { update of the } V \& V \text { checklists, TML } \\
\text { assessment, } V \& V \text { Dashboard, and concurrence that MRL- } 7 \text { V\&V requirement } \\
\text { have been met. }\end{array}$ \\
\hline
\end{tabular}


For an ICME application to be successful and to credibly support decision-making, rigorous verification and validation processes, including UQ, are essential. This is truly a critical requirement to ensure that program management, especially the chief engineers for the end product or application, and regulatory authorities, have confidence in the fidelity, maturity, and validation of model-based decisions.

4.2.4 Sub-thread 4: Definition and Execution of Critical Experiments. Experimental plans are always generated to support new material and manufacturing process development. These may be extensive and are intended to address many needs, ranging from basic properties to variation assessments, ICME model development, and design or structures data requirements. The specific recommendation made here, is that an integrated experimental strategy should be defined early in the technology development process, and that the experimental plan should specifically focus on definition and execution of "critical experiments," as a means of reducing risk and demonstrating capability for targeted conditions, geometries, and applications. "Critical experiments," in this context, are those experiments that can reproduce key conditions, test for required or critical attributes in a non-ambiguous manner, and provide objective, persuasive evidence that the manufacturing technology has matured to the level expected for a particular assessment gate or criteria. They may be part of a standard test protocol or plan, but more likely they may be a specially designed test to experimentally assess specific properties, capability, or attributes. The topic described as critical experiments, including development of an overall experimental strategy, was described in Section 3.6.5, and is included as a single sub-thread, "Definition and Execution of Critical Experiments."

\section{Intent and Rationale:}

- Technology development process includes extensive experimental effort

- ICME, associated V\&V, and key process parameter monitoring will add significant experimental knowledge and should be integrated

- Critical experiments should be defined in advance for key milestones or gates

- A comprehensive experimental strategy should be developed early

Attributes and Potential Benefits:

- Comprehensive experimental strategy will help integrate TRL and MRL efforts

- Definition of critical experiments will guide effort and provide objective measures of success - building early confidence and accelerating maturity

The importance of carefully defining critical experiments and associated success criteria, and the integration of these with the overall experimental plan, resulted in recommending this as a specific sub-thread for "Accelerated Manufacturing Technology Development.” Recommended activities and their alignment with MRL gates are presented in Table 6, below. Note that an initial experimental plan with notional description of critical experiments should be initiated early: here it is recommended at MRL-2. Subsequent activities are expressed as recommended gate exit criteria for key MRL gates. 
Table 6: Critical MT Experiments Sub-thread and MRL Alignment

\begin{tabular}{|c|c|c|}
\hline \# & $\begin{array}{l}\text { MRL } \\
\text { Level }\end{array}$ & Critical MT Experiments \\
\hline 1 & 2 & $\begin{array}{l}\text { Notional experimental plan defined, including progression from small, simple } \\
\text { geometry coupons through larger, complex geometry sub-elements and full- } \\
\text { scale articles. Integrated with TRL plans as appropriate. }\end{array}$ \\
\hline 2 & 3 & $\begin{array}{l}\text { High-level experiment plan established and budgetary requirements } \\
\text { determined by IPDT. }\end{array}$ \\
\hline 3 & 3 & $\begin{array}{l}\text { Process feasibility demonstration experiments defined and successfully } \\
\text { conducted. }\end{array}$ \\
\hline 4 & 4 & $\begin{array}{l}\text { Process application experiments defined and successfully completed } \\
\text { suitable for MRL4 level of application knowledge }\end{array}$ \\
\hline 5 & 5 & $\begin{array}{l}\text { Critical experiments for process demonstrations and success criteria for } \\
\text { specific applications defined in detail for MRL6, } 7 \text {, and } 8 \text { gate requirements. }\end{array}$ \\
\hline 6 & 6 & $\begin{array}{l}\text { Critical experiments for representative scale-up size and geometry features } \\
\text { successfully completed. }\end{array}$ \\
\hline 7 & 7 & $\begin{array}{l}\text { Critical experiments including use of "copy exactly" processing (if } \\
\text { appropriate) successfully completed on representative size and geometry } \\
\text { article(s). }\end{array}$ \\
\hline 8 & 8 & $\begin{array}{l}\text { Critical experiments including use of "copy exactly" processing (if } \\
\text { appropriate) and intended IPQA methods successfully completed on } \\
\text { detailed design-representative article }\end{array}$ \\
\hline
\end{tabular}

4.2.5 Sub-thread 5: Process Capability, Control, \& Quality Management. In the current MRL construct, there are separate threads for Process Capability and Control, and for Quality Management, each having three sub-threads. In practice they are, of course, closely related and integrated. The topics identified and evaluated as "in-process monitoring and advanced inspection techniques, from Section 3.6.4, and "feedback and updating processes, from Section 3.6.3, were combined into a single sub-thread: "Process Capability, Control, and Quality Management.” These were described extensively in Sections 3.6.3 and 3.6.4, so descriptions are not repeated here.

Intent and Rationale:

- Integrate items from several related Manufacturing Threads into a common strategy for process measurement, control and updating

- Define key process parameters and relate them to ICME, process modeling, and technology risk assessment

- Formalize a process-data updating method (Bayesian or alternative)

- Integrate in-process monitoring and advanced NDE methods

Attributes and Potential Benefits:

- Integrates all available process data for earlier maturation and confidence

- Integration of model-based knowledge with data to achieve more confidence earlier (target "six-sigma” or equivalent before MRL 8)

- Provide formal basis for continuous improvement vs. "frozen process" approach to maturation and improvement of new materials and process technology.

Distribution Statement A. Approved for public release (PA); distribution unlimited. 
Experimental data is continuously generated as a normal part of Manufacturing Technology and supporting ICME developments. This experimental data is important for demonstration and quantification of new process capability and output. It is also essential to define process limits and controls, to validate sensitivity and effect of key process parameters, and ultimately to validate and support process qualification for intended applications. This data is also important for another purpose: a rigorous and systematic updating process to refine and improve ICME models and parameters, including their variation, which are deemed important to represent the materials and manufacturing processes of interest. What is recommended as a result of this study task is systematic and disciplined use of updating and refinement methods for both the computational modeling efforts and the manufacturing processes themselves, beginning in the MRL 4 to 5 time period and continuing thereafter.

In-process quality monitoring, and advanced inspection capability, offer independent methods to validate process output, ensure processes are operating within defined limits, and even provide potential for closed-loop control of key process parameters that was not previously possible. While such capability would be very beneficial as independent elements, they can be especially effective when coupled with ICME-enabled material and process modeling, and uncertainty quantification of key model parameters and outputs. These methods offer potential to develop significant understanding of process capability, performance, and limits so that qualification for various applications can be greatly accelerated, and implementation risks greatly reduced.

This sub-thread describes activities which would be essential to integrate the ICME modeling efforts, as well as advanced process monitoring and NDE capability with traditional quality control and management, including statistical process control methods. The recommended activities are believed consistent with the AFRL Digital Thread initiative, and could be used to help define application-specific requirements for that initiative as part of manufacturing technology planning. The combination of these activities makes up the SEMT recommended sub-thread for Process Capability, Control, and Quality Management. The recommended timing and sequence is shown in relation to the MRL levels and Manufacturing Threads in Table 7. 
Table 7: Process Capability, Control and Quality Sub-thread and MRL Alignment

\begin{tabular}{|c|c|l|}
\hline$\#$ & $\begin{array}{c}\text { MRL } \\
\text { Level }\end{array}$ & \multicolumn{1}{c|}{ Process Capability, Control, and Quality Management } \\
\hline 1 & 4 & ICME Digital Thread amended and appended to support MT quality system. \\
\hline 2 & 5 & $\begin{array}{l}\text { ICME sensitivity study results and initial QC data applied to guide QC data } \\
\text { acquisition plan. }\end{array}$ \\
\hline 3 & 5 & $\begin{array}{l}\text { ICME system engineering tools applied to examine MT system dynamics, } \\
\text { robust MT system operation, and response surfaces to generate information to } \\
\text { aid MT control system development. }\end{array}$ \\
\hline 5 & 5 & $\begin{array}{l}\text { Key process and material parameters identified for active process monitoring } \\
\text { and control. Sensor, monitoring and key data requirements identified, and } \\
\text { integrated with ICME models and data feedback requirements. }\end{array}$ \\
\hline 6 & 6 & $\begin{array}{l}\text { ICMSE team has developed an approach and software to implement Bayesian } \\
\text { or equivalent updating to refine assessment of QC, ICME, and quality data. }\end{array}$ \\
\hline 7 & 7 & $\begin{array}{l}\text { Key process and material monitoring and control sensors and data } \\
\text { implemented into development process. Data and process output integrated } \\
\text { with ICME models. Continuous or periodic process update plans developed, } \\
\text { using data feedback and ICME models. }\end{array}$ \\
\hline 8 & 8 & $\begin{array}{l}\text { Integration of key process data and ICME models with UQ and variation } \\
\text { assessments completed. Level of Statistical Process Control determined, and } \\
\text { requirements to achieve Six Sigma equivalent control have been defined. }\end{array}$ \\
\hline & $\begin{array}{l}\text { Six-Sigma or equivalent certified process control achieved - and integrated with } \\
\text { ICME models and in-process monitoring approaches for periodic or continuous } \\
\text { feedback, sustainment, and improvement. Process variation monitored and } \\
\text { controlled. }\end{array}$ \\
\hline
\end{tabular}

4.2.6 Sub-thread 6: Manufacturing Management, Workforce Development, and Resources. Manufacturing Workforce, Facilities, and Manufacturing Management represent three separate threads in the current MRL construct. There are additional activities that are recommended in these areas as part of the SEMT thread. What was described in Section 3.6.6 as "other considerations,” was developed into a single sub-thread: Manufacturing Management, Workforce Development, and Resources.”

Intent and Rationale:

- Integrate manufacturing management and resource items from several related, existing Manufacturing Threads, to address SEMT requirements

- Address management education and advocacy building for ICME and related SEMT precepts

- Ensure manufacturing and engineering workforce skill development in SEMT methods and tools

- Identify facility and resource needs for SEMT success

Attributes and Potential Benefits:

- Education and skill development in computational models, methods and associated UQ and $\mathrm{V} \& \mathrm{~V}$ activities

Distribution Statement A. Approved for public release (PA); distribution unlimited. 
- Provide skills and methods to better integrate manufacturing with materials and engineering disciplines

- Education leads to advocacy - necessary to improve the current paradigm: iterative, empirical, frozen process, “freeze and characterize.”

It is believed that the most important activity here will be the need for materials and manufacturing engineering employee skill development, specifically in the areas of ICME, process modeling, V\&V, UQ, and potentially other methods as described in this study task report. These skills are expanding, but are not yet broadly available in the workforce. Consequently, training and skill development in specific topics as described may be necessary for acceptance and successful implementation of the study task recommendations. Education and commitment of manufacturing management will also be essential: first to understand and advocate for the recommended SEMT activities, and then to ensure early and continuous commitment of required resources. Increased use of computational modeling, integration of process development and process-monitoring data, NDE results, automated data collection and analysis for feedback - will necessitate investment in equipment, data bases, personnel, and software. Collectively, a commitment to SEMT activities offers enormous potential for benefits in time, cost, and risk for MT development and implementation: but achieving these benefits will require that manufacturing management understand and support the infrastructure and workforce requirements. The timing and sequence of recommended activities are shown in relation to the MRL levels in Table 8.

Table 8: Manufacturing Management, Workforce Development, and Resources Sub-thread and MRL Alignment

\begin{tabular}{|c|c|c|}
\hline \# & $\begin{array}{l}\text { MRL } \\
\text { Level }\end{array}$ & $\begin{array}{c}\text { Manufacturing Management, Workforce Development, and } \\
\text { Resources }\end{array}$ \\
\hline 1 & 3 & $\begin{array}{l}\text { MT IPDT has briefed management on the planned system engineering approach, } \\
\text { integration with the related TRL activities, and expected quality, acceleration, and risk } \\
\text { reduction benefits. }\end{array}$ \\
\hline 2 & 3 & $\begin{array}{l}\text { MT IPDT has provided management with a plan and cost analysis for the MT system } \\
\text { engineering effort. }\end{array}$ \\
\hline 3 & 3 & $\begin{array}{l}\text { MT management has committed sufficient funds and internal workforce resources to } \\
\text { execute systems engineering acceleration activities. }\end{array}$ \\
\hline 4 & 4 & $\begin{array}{l}\text { MT IPDT has provided to management a manpower plan that distinguishes between } \\
\text { in-house and out-sourced manpower (and associated rationale and costs). }\end{array}$ \\
\hline 5 & 4 & $\begin{array}{l}\text { MT management has committed to provide resources that support computer, } \\
\text { database, and computational software associated with ICME, V\&V, and Digital } \\
\text { Thread activities. }\end{array}$ \\
\hline 6 & 4 & $\begin{array}{l}\text { MT IPDT has provided a summary of workforce expertise needs (i.e., in ICME, } \\
\text { process modeling, V\&V, UQ, and leftward implementation of system engineering } \\
\text { technologies) to achieve a long-term MT improvement and subsequent sustainment. }\end{array}$ \\
\hline 7 & 4 & $\begin{array}{l}\text { MT management has committed to provide sufficient MT development facilities (or a } \\
\text { fair time share) to support ICME and associated systems engineering development } \\
\text { activities. }\end{array}$ \\
\hline 8 & 5 & $\begin{array}{l}\text { Workforce development activities for training in ICME, UQ, V\&V, and In-process } \\
\text { monitoring methods planned and initiated. }\end{array}$ \\
\hline
\end{tabular}

Distribution Statement A. Approved for public release (PA); distribution unlimited. 
Note that significant activities related to SEMT align with MRL-3, 4, and 5. These activities are not intended to supersede any of the similar activities which appear in related Manufacturing Threads under the current MRL construct, but rather to initiate them earlier and to ensure focus on the requirements and recommendations found in the SEMT Thread.

\subsection{Alignment of SEMT with the MRL Process and Manufacturing Threads}

The proposed new Manufacturing Thread: "Systems Engineering for Manufacturing Technology" has been defined, along with the six sub-threads that contain recommended activities and their proposed sequence. These were described in some detail in the previous sections of this report, and are presented in tabular form in Tables 3 through 8, along with proposed alignment with MRL gates. The intent was to ensure close alignment and compatibility with the current MRL/MRA process.

It is recognized that some of the activities recommended in the SEMT thread are represented in other, existing threads. In these cases, it is believed that the SEMT thread advocates earlier initiation of specific activity, and in most cases provides a more defined set of activities and how these should be integrated with other manufacturing threads. References, historical perspective, and some examples were provided in Section 3.6 of this report.

Illustrating the entire MRL gate structure, with all nine current threads, is difficult without reducing detailed entries to unreadable size. It is, however, useful to show the alignment of the proposed SEMT thread, and its six proposed sub-threads, with the MRL gates and the important corresponding DoD Acquisition Milestones: A, B, and C. This alignment is shown in Figure 9, below. Please note:

1. The "Systems Engineering for Manufacturing Technology (SEMT)" thread spans the entire MRL gate regime, although gate criteria have not yet been defined for some MRL levels.

2. Six sub-threads comprise the recommended activities and have been individually aligned with MRL gates.

3. Significant activity is recommended early in the MRL process: defined actions are included under MRL 2 and 3, and most activity is defined prior to Milestone B, at conclusion of MRL 6.

The details of the proposed activities, and their alignment with the MRL gates, represent an initial proposal based on this brief Study Task and the feedback which was received during its execution. A thorough review and, ideally, some trial application, would undoubtedly result in some revision and improvement. 


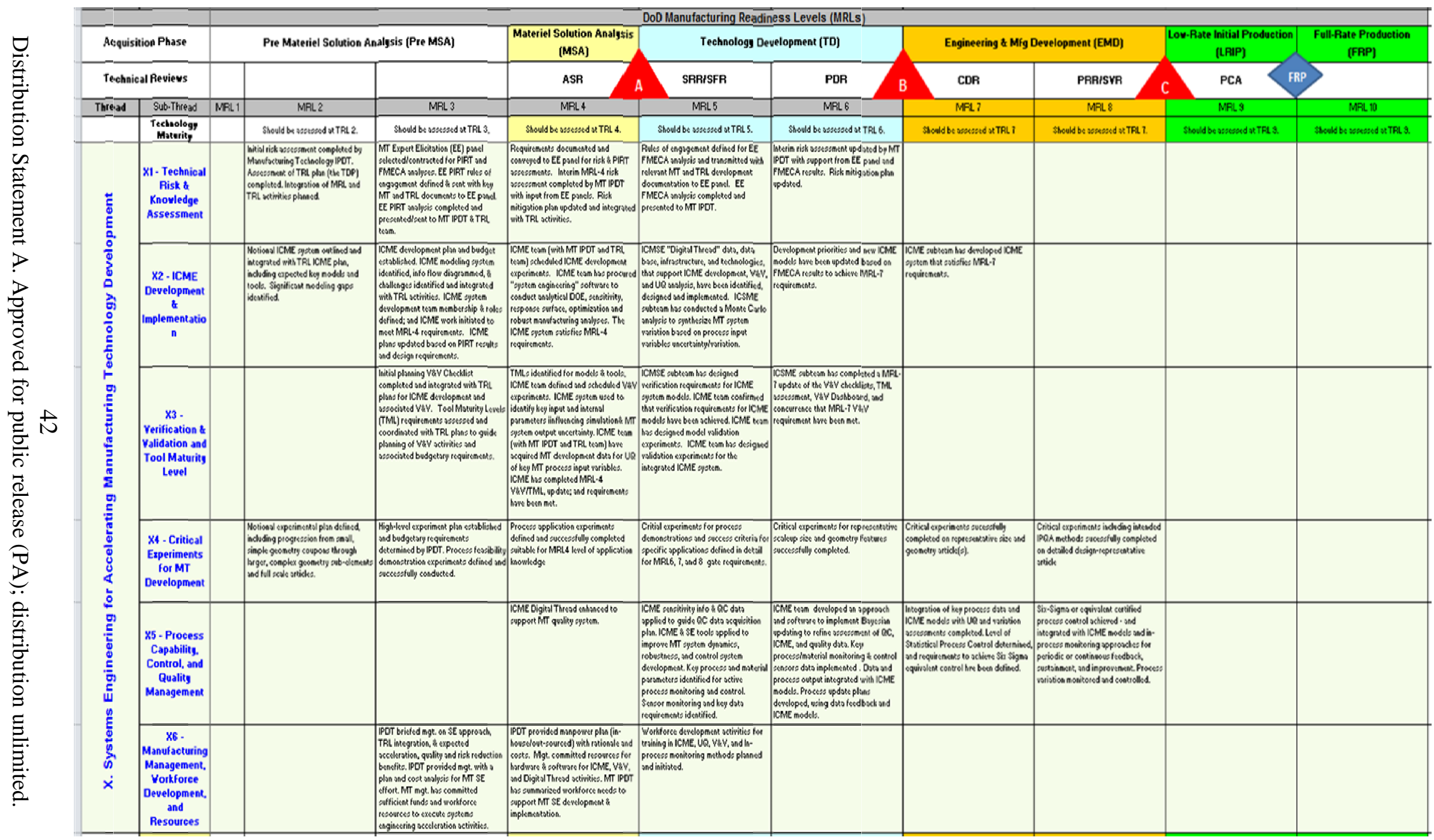

Figure 9: Alignment of Proposed SEMT Thread and Six Sub-threads with MRL Gates Note significant activity in MRL 2 and 3 and focus prior to Milestone $B$ 


\subsection{Recommended Decision Questions for When to Employ SEMT}

The proposed activities recommended for SEMT represent a significant commitment of time and resources. Consequently, the decision to employ some or all of the recommended SEMT processes should be carefully considered. The perspective on the need for such activities may differ, depending on whether the perspective is that of the technology or process developers, the product or system chief engineers, or the program management (or the systems acquisition management). A joint assessment and consensus decision would be ideal, although an assessment may be required before system or product application targets can be well-defined. A set of eight (8) questions was developed to assist making an objective decision regarding implementation (or requirement) of the SEMT process. The questions were divided into two categories:

- Technology and Process Development Questions - these were intended to assist assessment of the manufacturing technology or process development itself, and

- System or Product Implementation Questions - these were intended to assist assessment of the impact the manufacturing or process technology could have on the intended application, especially if MT development was late or not fully successful to meet system or product requirements.

Since the eight questions were necessarily high-level, a set of sub-questions was also developed. The sub-questions were intended to clarify intent and scope of the Key Questions, and provoke an objective assessment of the need for the SEMT process. The questionnaire is presented in Table 9, below.

The recommended approach to complete the questionnaire is to review and answer each subquestion, and then determine the overall answer to the corresponding Key Question. Questions were written to solicit a simple Yes or No response to each item. Selected answer boxes have a bold outline and yellow fill color: if the answers to one or more sub-questions are in such a highlighted box, it implies that the Key Question answer should be in the corresponding highlighted box. If the answers to any of the Key Questions numbered Q1, Q3, Q4, Q6, Q7, or Q8 are "Yes," the recommendation is that SEMT processes be implemented. Key Questions Q2 and Q5 may indicate risk can be mitigated, or decision to employee SEMT delayed, based on other applications of the candidate technology, or pending better definition of product or system application requirements.

The questionnaire was developed with the knowledge (and intent) that both the manufacturing technology development team leaders, and the product or system application engineers, would likely be required to completely answer the questions. 
Table 9: Proposed Decision Questionnaire for Use of SEMT Process

Utilization of Systems Engineering for Manufacturing Technology (SEMT)

Key Questions to Assist Implementation Decision

Technology and Process Development Questions

\begin{tabular}{|c|c|}
\hline \multicolumn{2}{|c|}{$\begin{array}{c}\text { Support } \\
\text { Questions }\end{array}$} \\
\hline Yes & No \\
\hline
\end{tabular}

1 Is this a new technology or manufacturing process for aerospace application? Does MT development involve a new class of material?

Does MT development represent a new manufacturing process?

Does MT development represent more than a derivative or upgrade of existing technology?
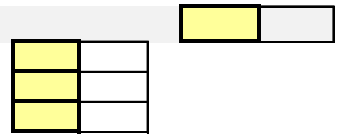

$2 \quad$ Has the manufacturing technology or process been used for a non-aerospace application? Does this application have stringent (aerospace-like) quality, performance, and durability requirements? Is there available literature \& data to judge the suitability of the MT for aerospace applications?
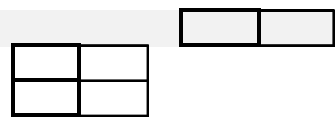

3

Have significant technical risks been identified for the manufacturing technology or process? Has a risk analysis been performed?

Did the risk analysis identify any significant risks?
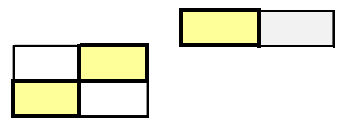

$4 \quad$ Will new infrastructure or supply base capability be required?

Does existing supply base require new or additional capital infrastructure?

Are significant new investments/development required for production?

Does supply base require development of new or significantly different skill sets?

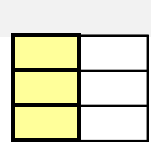

System or Product Implementation Questions

$5 \quad$ Has a system application of the technology or process been identiifed? Target application or component/part family identified?

Target system for implementation identified?
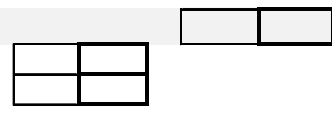

Is the acquisition program accelerated (per Interim DODI 5000.02)?

Are Technology Development and EMD activities planned to overlap? (Model 1)

Are Technology Development and EMD concurrent? (Designated as an Accelerated Program, Model 4)
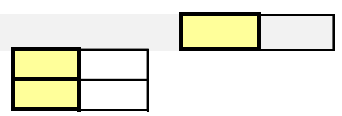

7 Does the technology/process maturation schedule represent a risk for system requirements? Is the technology and/or MT expected to be identified as a "critical technology?" Risk that technology/process will not achieve TRL/MRL 4 prior to Milestone A? Risk that technology/process will not achieve TRL/MRL 6 prior to Milestone B? Risk that technology/process will not achieve TRL/MRL 8 prior to Milestone C?
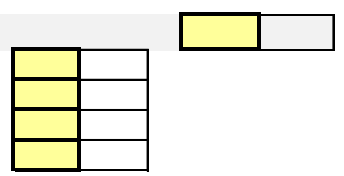

8 Is the Technology/Process Strategic to the System or Product? If technology/process is late to schedule, will system or product be delayed?

Will an acceptable backup for the technology/process be carried as risk mitigation?

If technology/process fails to mature, will system or product arcitecture have to change?
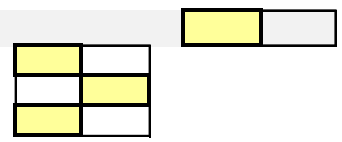

\section{Notes:}

1 Sub-question

2 Key Technology Questions: If answer to Q1, Q3, or Q4 is Yes, Implement SE4QRS recommended actions. May be mitigated or delayed if answer to Q2 is Yes.

3 Key System or Product Implemenation Questions: If answer to Q6, Q7, or Q8 is Yes, Implement SE4QRS recommended actions. May be mitigated or delayed if answer to Q5 is No.

It is recommended that this questionnaire be used early in the planning of an MT program. The intent is to provoke an objective assessment of the risks posed by a new technology, especially to the intended system or product application. As such, any manufacturing technology program would likely benefit, whether the intended application is a "quick reaction system," a designated “accelerated acquisition program,” or even a modification to an existing system or product.

Distribution Statement A. Approved for public release (PA); distribution unlimited. 


\subsection{CONCLUSIONS}

The current processes and guidelines used by DoD and the Air Force for manufacturing technology and production readiness assessment were reviewed under this study. The MRL and MRA processes, considerations, and gate exit criteria were reviewed in detail. Several focus areas were identified and evaluated as candidate methods or processes that could accelerate maturation of new materials and manufacturing technologies, and reduce the risk of their implementation. These focus areas were refined, and feedback from several manufacturing technology experts in AFRL and industry was solicited and incorporated.

The resulting topics comprise a suite of recommended activities that collectively were termed "Systems Engineering for Manufacturing Technology (SEMT)." The individual technical topics that were identified, as well as supporting infrastructure and management activities, were consolidated into six defined focus areas. These are:

1. Technical Risk and Knowledge Assessment: including expert elicitation, risk assessment and mitigation methods, and non-advocate review processes

2. Integrated Computational Materials Engineering (ICME): including development of a strategy for comprehensive computational modeling for materials, processing, and properties, including identification of parameter sensitivity and variation

3. Verification \& Validation and Tool Maturity Level: including rigorous model V\&V, uncertainty quantification, and assessment of analytical or computational tool maturity compared to application requirements

4. Definition and Execution of Critical Manufacturing Technology Experiments: including a strategy for integration of the entire planned experimental program and the definition of critical demonstration experiments

5. Process Capability, Control and Quality Management: including early assessment of key process parameters, use of in-process monitoring and control, advanced NDE methods, and Bayesian or other continuous updating of process outputs and models

6. Manufacturing Management, Workforce Development, and Resources: including management education and commitment regarding ICME and other topic areas required for SEMT, workforce development in SEMT areas, and planning and commitment of facilities and resources to accomplish SEMT activities per required development plans.

The current MRL/MRA process is well defined and accepted; it is also comprehensive in both scope and application. When properly practiced, it effectively assesses and reduces implementation risks for new manufacturing technologies. The proposed SEMT activities are aligned with the current practice, and offer the potential and recommended activities to enhance its effectiveness, accelerate maturation of new technologies, and reduce their risk of implementation.

How to effectively implement the suite of activities represented by SEMT presents a significant challenge. Conceptually, the six focus areas were viewed as possible recommended additions to the current MRL/MRA and Manufacturing Thread construct. Each of the six defined focus areas was assessed for compatibility with the current MRL gate criteria and the current Manufacturing Threads. Notional activities were defined for each focus area, and aligned with appropriate MRL 
gates. The SEMT activities could be inserted within the current framework in a piecemeal fashion, inserted as an additional Manufacturing Thread, or developed as a separate best practice or guideline, compatible with the current process.

The proposed activities recommended for SEMT represent a significant commitment of time and resources. Consequently, the decision to employ some or all of the recommended SEMT processes should be carefully considered, and should involve input from technology or process developers, the product or system chief engineers, and the program management (or the systems acquisition management). A one-page questionnaire was developed to assist making an objective decision regarding implementation (or requirement) of the SEMT process. The questions were divided into two categories: one representing the subject technology and the other category representing the system or application perspective of risk.

The key conclusions from the Study Task can be summarized as follows:

1. It was concluded that the recommended activities within the six defined focus areas offer the potential to greatly accelerate maturation of new materials and manufacturing technologies, and significantly decrease their risk of implementation.

2. One key conclusion under this Study Task was that these six focus areas - including both strategies and methods - would be most effective if employed in an integrated, iterative, and collective manner. They would not be nearly as effective if applied individually or independently.

3. The proposed SEMT activities are fully aligned and consistent with intent of the current MRL/MRA process.

4. The proposed SEMT activities were defined in a manner that would enable inserting SEMT as an additional Manufacturing Thread, within the current MRL/MRA process.

5. Alternatively, it was concluded that the SEMT activities could be developed into an engineering or program best practice or guideline, and implemented within the current MRL/MRA process as a means to accelerate designated activities. This approach could be implemented without requiring any modification to the current MRL/MRA process. This approach is regarded the preferred path.

6. It was concluded that a decision process for when to implement SEMT was required. A one-page questionnaire was developed with high level questions intended to objectively assess risk of the technology itself, and also the risk posed for the system or product application.

The most significant challenge for this Study Task was to identify, define, and recommend processes and/or methods that could effectively accelerate maturation of manufacturing technologies, and to provide confidence to key decision-makers that such technologies could be successfully implemented, with an acceptable level of risk. A set of activities was identified and 
evaluated, with potential to accomplish these goals. These focus areas have been aligned with the current established MRL process, and recommendations for how to implement SEMT as an either as an optional $10^{\text {th }}$ Manufacturing Thread, or, alternatively, as a best practice or guideline have been made. 


\subsection{RECOMMENDATIONS}

This brief "Phase 0" Study Task was intended to review current practices and background information, identify and evaluate promising methods or processes with potential to significantly accelerate maturation of manufacturing technologies, and to provide confidence to key decisionmakers that such technologies could be successfully implemented with an acceptable level of risk. A set of activities defined as "Systems Engineering for Manufacturing Technology (SEMT)" was been identified and evaluated, The six focus areas comprising SEMT were aligned with the current established MRL process, and recommendations for how to incorporate them have been made. Although several manufacturing technology experts did review the concepts and proposed focus areas during the course of this study task, the results in this final report have not yet been comprehensively reviewed.

Consequently, the near-term focus for future activities is on presenting the SEMT concept to interested parties in government and industry, soliciting feedback and constructive criticism, and incorporating recommended revisions. The objective is to solicit not only feedback, but hopefully support and advocacy for implementation of SEMT in some manner, either as part of the established MRL/MRA process, or as Recommended Best Practice or engineering or program work instruction. This would ideally involve at least the following recommended steps:

1. Presentation and reviews with AFRL/RXM, MAI, and possibly others are recommended. These reviews could be constructed and abbreviated from the final summary presentation, which was delivered by the authors to AFRL/RXM on 23 July 2014.

2. Distribution of the Study Task Final Report to interested parties for review and feedback is recommended.

3. Review with the JDMTP committee, as the owners of the MRL/MRA process, is recommended. This is regarded important, whether SEMT is advocated as an additional Manufacturing Thread or, alternatively, as a best practice or guideline process.

Provided that response regarding proposed SEMT activities is positive and supportive, the following actions are also recommended:

4. Development of some plans specifically for SEMT revision, beta-testing and an initial application exercise under an actual manufacturing technology program is recommended. It may be advisable to select an existing candidate MT program, where the planning and strategy aspects of SEMT could be exercised independent of the existing program plan and statement of work. Ideally, a program could be selected - existing or new start - where SEMT would be appropriate and could be fully exercised.

5. It is recommended that an approach or plan identifying the implementation path and actions required. This may be to define SEMT in the form of engineering or 
program instruction, a best practice or guideline, or an ad-hoc addition to the MRL/MRA process.

\section{Community reviews and focus sessions are recommended, via Technology Interchange Meetings or workshops to engage Original Equipment Manufacturers, suppliers, and government experts.}

\section{An effort to produce a final (Version 1) SEMT Guideline suitable for} implementation. The form this would take would be dependent upon outcome of Recommendation 5, above.

Although no specific time-line is recommended for the above items, it is recommended that Items 1, 2, and 3 be addressed in calendar year 2014. Items 4, 5, and 6 are contingent on outcome of Items 1, 2, and 3, and would follow, probably beginning in early 2015.

Overall, the proposed SEMT manufacturing thread, with its six focus areas defined as subthreads, represents a comprehensive and integrated set of activities. It is believed that SEMT would be a very useful addition, revision, or supplement to the current MRL/MRA process. In addition, it is believed that SEMT may prove to be a very useful set of activities in support of three significant AFRL/RXM focus areas: Moving Manufacturing Left (MML), Agile Manufacturing, and Digital Thread. 


\subsection{REFERENCES}

1. Defense Acquisition Guidebook, Production Date: 28 June 2013, available at https://acc.dau.mil (accessed 28 July 2014).

2. Department of Defense Instruction DODI 5000.02, "Operation of the Defense Acquisition System,” December 8, 2008.

3. GAO Report "Defense Acquisitions - Major Weapons Systems Continue to Experience Cost and Schedule Problems Under DoD’s Revised Policy,” GAO-06-368, March 2006.

4. GAO Report "Best Practices - DoD Can Achieve Better Outcomes by Standardizing the Way Manufacturing Risks Are Managed,” GAO-10-439, April 2010.

5. Interim DoD Instruction 5000.02, "Operation of the Defense Acquisition System," November 25, 2013.

6. Sadin, Stanley T.; Povinelli, Frederick P.; Rosen, Robert; "NASA Technology Push Towards Future Space Mission Systems,” Acta Aeronautica, V 20, 1989, pp. 73 - 77.

7. AFRL Fact Sheet for Joint Defense Manufacturing Technology Panel (JDMTP), available at: http://www.wpafb.af.mil/library/factsheets/factsheet.asp?id=9758

8. DoD MRL website. Access at: http://www.dodmrl.com

9. $\quad$ MRL Overview chart, available at: http://www.dodmrl.com/MRL_Overview_Chart.pdf

10. National Research Council. 2011. Materials Needs and R\&D Strategy for Future Military Aerospace Propulsion Systems. pg. 29-33. Washington, D.C.: The National Academies Press.

11. Strategic Materials: Technologies to Reduce U.S. Import Vulnerability, Washington, DC: U.S. Congress, Office of Technology Assessment, OTA-ITE-248, (May 1985)

12. N.T. Saunders, Cost Analysis of Advanced Turbine Blade Manufacturing Process, Final Report for Contract NAS 3-20378, prepared for NASA-Lewis Research Center, NASA CR-135203 (1977).

13. A. Lambourne, Spray forming of Si-Al Alloys for Thermal Management Applications, Ph.D. Thesis, Queen's College, University of Oxford, (2007).

14. S.A. Singerman and J.J. Jackson, Titanium Metal Matrix Composites for Aerospace Applications, Superalloys 1996, ed. R.D. Kissinger, etc. The Minerals, Metals \& Materials Society, 1996, pg. $579-586$.

15. National Research Council (NRC), Integrated Computational Materials Engineering: A Transformational Discipline for Improved Competitiveness and National Security, Washington, D.C., The National Academies Press, 2008

16. National Research Council (NRC), Application of Lightweighting Technology to Military Aircraft, Vessels, and Vehicles, Washington, D.C., The National Academies Press, 2012

17. Integrated Computational Materials Engineering (ICME): Implementing ICME in the Aerospace, Automotive, and Maritime Industries, A Study Organized by The Minerals, Metals \& Materials Society, Warrendale, PA, 2013.

18. Office of Science and Technology Policy (OSTP). "Materials Genome Initiative for Global Competitiveness,” June, 2011. Available at: http://www.whitehouse.gov/sites/default/files/microsites/ostp/materials_genome_initiativ e-final.pdf. 
19. The American Society of Mechanical Engineers, "Guide for Verification and Validation in Computational Solid Mechanics,” ASME V\&V 10-2006

20. Cowles, Backman, and Dutton: Verification and validation of ICME methods and models for aerospace applications. Integrating Materials and Manufacturing Innovation 2012 1:2. See also: http://www.immijournal.com/content/1/1/2

21. Cowles and Backman, "Verification and Validation of ICME Methods and Models for Aerospace Applications: V\&V Guidelines and Recommended Best Practice, Revision 1" AFRL-sponsored white paper document, distributed 1 December 2013. Distribution Statement A: Approved for public release; distribution unlimited.

22. Cowles and Backman, "Verification and Validation of ICME Methods and Models for Aerospace Applications: V\&V Guidelines and Recommended Best Practice, Revision 1" Excel $^{\mathrm{TM}}$ spreadsheet tools and practitioner aides, AFRL-sponsored white paper document, distributed 1 December 2013. Distribution Statement A: Approved for public release; distribution unlimited. 


\section{APPENDIX: EXPERT ELICITATION}

Successful expert elicitation (EE), whether using Phenomena Identification and Ranking Technique (PIRT), Failure Mode, Effects, and Criticality Assessment (FMECA), or other methods, depends foremost on having a high level of commitment to EE within the MT development team, particularly among the IDPT leadership. Unenthusiastic effort in composing, instructing, and/or informing the EE team, will weaken EE team performance and lessen the benefits of the EE team's work.

As a prelude to selection of EE panel members, the IPDT can conduct preliminary PIRT and risk assessment exercises to identify those elements of the MT development that are most important, least well understood, or subject to risk; and also list relevant successor technologies. Armed with this information, the IPDT can better focus the EE panel selection process on key categories of expertise of greatest importance to the MT development program; and gain clues as to where the IPDT can find the right experts, whether from within the resident engineering staff, academia, government laboratories, or other industries involved in related MT sub-processes.

First, the IPDT needs to identify a group of willing experts that collectively span the breadth and depth of the lesser-known process steps of the subject manufacturing technology. These team members should be independent, meaning they should not have a vested interest in the EE outcome or the success of the MT program [A-1]. Although assembling such a team is often not easy, the quality of the EE team findings and recommendation depend on finding highly experienced and knowledgeable experts, preferably individual unafraid to challenge the manufacturing technology under consideration or the technical viewpoints and analysis of the IPDT membership. Indeed, the IPDT leadership should encourage a skeptical outlook on the part of EE team members.

Second, the IPDT needs to provide the EE team with explicit instructions so that it clearly understands the scope and objectives of the exercise, along with instructions for the EE process(es) that will be used in the investigation. The EE team should not be allowed to either assume or define the scope or objectives of the EE exercise without consulting with the IPDT and gaining approval for any change that the EE team might recommend [A-1].

Third, the IPDT needs to collect and disseminate information to the EE team to provide MT technology background, development status, and specific technical perspectives of IPDT members. This input would include the following types of information [A-1]:

- An overview of the MT development program, requirements, perceived challenges, and expected benefits;

- Historical information describing related predecessor or constituent processing technologies, along with their strengths and weaknesses;

- A summary of the target manufacturing technology that includes a flow diagram of process steps, description of intended processing equipment, and identification of new or unfamiliar steps;

- Thorough documentation describing state-of-development for the manufacturing technology including important operational experience, data, and suspected shortcomings

52

Distribution Statement A. Approved for public release (PA); distribution unlimited. 
- Information relative to key process phenomena, ICMSE capability, process sensing, inprocess NDE, and testing of intermediate product;

- The results from any risk analysis and/or PIRT/FMECA exercises conducted by the IPDT team; and

- Candid discussion about the spectrum of issues, questions, risks, and other perspectives within the MT IPDT that collectively should explain why the EE team was empanelled.

In some regards the expert elicitation team should function much like a "Red Team" review panel, albeit one that exercises a well-defined EE process. And much like the effectiveness of "Red Team" reviews, the success of expert elicitation depends very strongly on whether IPDT leadership believe the process is a meaningful resource to enhance their MT development progress - as opposed to simply being a process needed to comply with a contract checklist requirement or a preference of the program sponsor.

Phenomena Identification and Ranking Technique (PIRT)

The US Nuclear Regulatory Commission developed PIRT" in 1989 as part of their "Code Scaling, and Applicability” effort [A-1]. The premise of PIRT is to gather information about phenomena governing subject process/equipment from a panel of experts. The EE team ranks the importance and state-of-process knowledge for the phenomena to support program decision making, which includes identification of key unknowns and help to define research that will fill important knowledge gaps [A-2]. In execution, this strategy identifies and ranks phenomena based on their effect upon key manufacturing and product requirements, referred to as the figures-of-merit (FoM). Application of PIRT should adopt a hierarchal approach that starts with lower-level process sub-steps and proceeds upwards towards the complete system. The PIRT strategy is executed in four successive steps, including the PIRT scoring table shown in Figure A-1:

1. Identify phenomena that control process outcomes. Phenomena can be: characteristics of input materials, design elements of manufacturing equipment, a process parameter window, a control algorithm, a mechanism within a ICMSE model, or anything else that might influence the FoMs;

2. Estimate the level of importance for each phenomena as it affects each FoM, using the rating system outlined below;

3. Estimate the level of knowledge uncertainty for each the phenomena using the rating system below;

4. Collect, enumerate, and tabulate the ratings from the EE panel members and calculate the overall importance and uncertainty rankings using the collective voting results from the team.

Importance Level (how much do the Phenomena affect the FoM):

1. High (H) implies phenomenon (or parameter, model ...) has a controlling impact on a given FoM.

\footnotetext{
${ }^{4}$ PIRT is a widely known process that is well documented in the literature, much of which is available on the web. This description of PIRT attempts only to capture the highlights and provide a simple representation of supporting charts used for analysis. Interested readers are encouraged to read the documents referenced herein.
} 
2. Medium (M) implies phenomenon has moderate impact on a FoM \& only moderate accuracy is required for manufacturing parameters, measurements, controls, or associated models.

3. Low (L) implies the phenomenon has very little or no impact on the FoM.

Knowledge Level_(how well understood is the phenomenon, parameter or model):

1. Known (K) implies knowing at least $75 \%$ of what we could expect to be known.

2. Partially Known (P) implies that $25-75 \%$ of needed knowledge is established.

3. Unknown (U) implies that less than $25 \%$ of needed knowledge is established.

After the EE panel has completed the PIRT ranking table (Figure A-1), the panel and the MT IPDT can use the results to help focus the development program. The teams can identify those phenomena upon which research is needed by plotting knowledge uncertainty versus phenomena importance, as depicted in Figure A-2.

\begin{tabular}{|c|c|c|c|c|c|c|c|c|c|}
\hline \multirow[b]{2}{*}{$\begin{array}{c}\text { Subcategory } \\
\text { (within the } \\
\text { phenomena hierarchy) }\end{array}$} & \multirow[b]{2}{*}{ Phenomenon } & \multicolumn{4}{|c|}{$\begin{array}{l}\text { Phenomena } \\
\text { Importance }\end{array}$} & \multicolumn{4}{|c|}{$\begin{array}{l}\text { Knowledge } \\
\text { Uncertainty }\end{array}$} \\
\hline & & $\mathbf{H}$ & M & $\mathbf{L}$ & IR & $\mathbf{U}$ & $\mathbf{P}$ & $\mathbf{K}$ & UR \\
\hline \multirow[t]{6}{*}{$\mathrm{SC} 1$} & P1 & NE1 & NE2 & NE3 & R1 & NE4 & NE5 & NE6 & $\mathbf{R 2}$ \\
\hline & P2 & & & & & & & & \\
\hline & P3 & & & & & & & & \\
\hline & P4 & & & & & & & & \\
\hline & P5 & & & & & & & & \\
\hline & P6 & & & & & & & & \\
\hline \multirow[t]{6}{*}{$\mathrm{SC2}$} & P7 & & & & & & & & \\
\hline & P8 & & & & & & & & \\
\hline & P9 & & & & & & & & \\
\hline & P10 & & & & & & & & \\
\hline & P11 & & & & & & & & \\
\hline & P12 & & & & & & & & \\
\hline
\end{tabular}

NOTES:

(1) NE1 thru NE6 represent the number of experts scoring these categories

(2) Importance Ratio (IR) $=($ NE1 +0.5*NE2) / (NE1 + NE2 + NE3)

(3) Uncertainty Ratio (UR) $=($ NE4 +0.5*NE5) / (NE4 + NE5 + NE6)

(4) The Uncertain Scale (defined in note \#3) is the inverse of that used by Diamond (2)

Figure A-1: The PIRT ranking table enumerates the number of PIRT panel members who rate importance in the $H / M / L$ columns and knowledge uncertainty in the $U / P / K$ columns. Formulas shown in the notes are then applied to calculate the "importance ranking" (IR) and the "uncertainty ranking" (UR) 


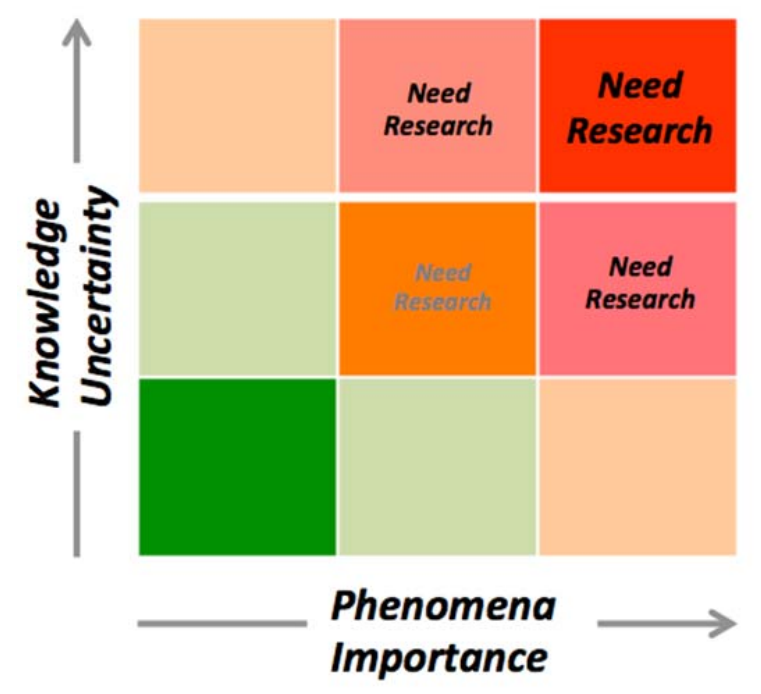

Figure A-2: The PIRT ranking table plots "importance ranking” (IR) and "uncertainty ranking” (UR) for each phenomena to provide a graphical view of where research is needed

This chart, when compared to initial IPDT risk assessments, can highlight those phenomena and their associated process steps that may pose potential locations for Unk-Unk risk. The PIRT process is particularly valuable during early stages of MT development (or even during preprogram planning), whether conducted by the IPDT alone or in conjunction with an independent EE panel.

This section attempts to provide an overview of PIRT; indeed there are many exhaustive reports describing the process, some of which are listed in the references. Foremost, however, IPDT teams need to understand the underlying PIRT concept, rationale, and general approach, and then tailor a PIRT exercise to their programs needs. As espoused before, early application of EE and the inclusion of independent experts in the PIRT process can significantly enhance program success by reducing the incidence of unexpected surprises that may require program redirection, added cost, and possibly even abandonment.

Failure Mode, Effects, and Criticality Assessment (FMECA)

NASA developed the FMECA process to improve and verify the reliability of space program hardware. The process is documented in MIL-STD-1629 and is extensively discussed in a 1993 DLA/DTIC report [A-3]. NASA's premise for FMECA was to gather information from experts who are charged to identify potential failure modes for a system or product, assess their effect, and then determine the criticality of the failure in support of program decision-making. While developed for space program hardware, FMECA has been applied to a wide variety of other systems and is certainly applicable to manufacturing development technologies - including both the manufacturing process and the resulting manufactured product. It's also important to note that the IPDT and EE panel can flexibly define the word "failure" to conform to the specific needs of the FMECA assessment. In other words, failure might mean might failure of process sensor, but it could also refer to excessive variation for a critical-to-quality (CTQ) product attribute, etc. It's also useful to contrast FMECA with the PIRT process. Whereas, PIRT strives to identify key phenomena and then deduce their effects and associated knowledge gaps; 
FMECA attempts to evaluate hypothetical failure modes (what might go wrong) and then evaluate their likelihood and impact. As such, FMECA represents a much different, but complementary, thought process from that used by PIRT.

The more qualitative, functional FMECA approach is likely most germane to early manufacturing technology development. This approach follows the following steps:

1. Identifying potential, signification MT process mishaps, disruptions, or failures relative either to MT process flow or product attributes. Failure might be: formation of a material defect, excessive residual stress, properties outside specification limits, inadequate NDE probability of detection, process control instability, or excessive variability of process parameters, etc.

2. Determining the severity of the "failure" upon associated FoM's;

3. Estimating the probability of "failure; and

4. Estimating the joint probability that the effect or "failure" will be detected using process diagnostics or NDE.

5. Finally, the assessment team should aggregate and interpret results based on the FMECA chart, shown in Figure A-3.

Given the likely lack of detailed process data, for steps 2 through 4 early in the program, the IPDT team should rank the items \#2 through \#4 qualitatively based on team judgment using a 15 scoring system. There are a number of FMECA resources available in the literature that can provide additional insight on how to best execute this process for a given MT development program. Also, prior to committing to an EE exercise, the team must assess whether the MT development represents a MT refinement or a greater leap forward. It must also judge the IPDT level of knowledge about new manufacturing technology domain that will be explored during the manufacturing development program. These judgments are critical to program success; and potential risks can be lessened when the team acknowledges program deficiencies and accepts that there may be experts in seemingly unrelated fields that can provide very useful guidance.

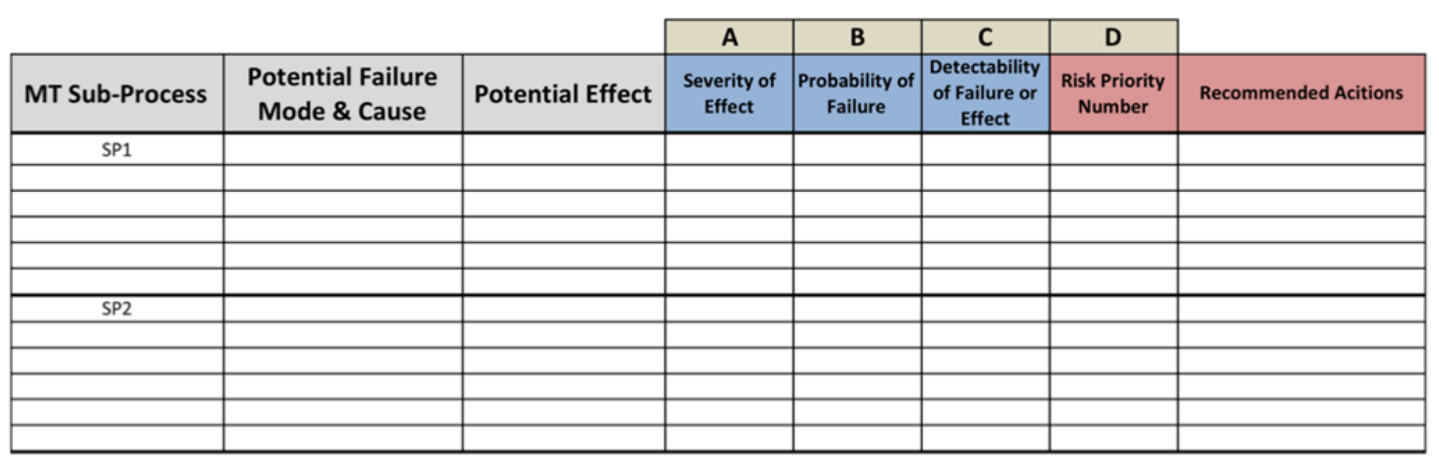

Notes: (1) Entries under the "Potential Effect" column should specify the requirement (FoM) effected;

(2) Numeric values should be used to score columns A, B, C (e.g., 1-10)

(3) Risk Priority Number: $D=A *(1-B) *(1-C)$

Figure A-3: Typical chart used to tabulate FMECA results and then calculate analysis 


\section{References - Appendix}

1. Risk and Safety Working Group, "An Integrated Safety Assessment Methodology (ISAM) for Generation IV Nuclear Systems,” Report GIF/RSWG/2010/002/Rev1, Version 1.1, June (2011).

2. D.J. Diamond, "Experience Using Phenomena Identification and Ranking Technique (PIRT) for Nuclear Analysis”, Brookhaven National laboratory report BNL-76750-2006CP, (2006).

3. "Failure Mode, Effects and Criticality Analysis (FMECA)", Reliability Analysis Center, Rome NY, DLA/DTIC Report \# F30602-91-C-0002, (April 1993).

4. National Research Council (NRC), Integrated Computational Materials Engineering: A Transformational Discipline for Improved Competitiveness and National Security, Washington, D.C., The National Academies Press, 2008.

\section{Additional PIRT references:}

5. M. Holbrook, "Phenomena Identification and Ranking Technique (PIRT): Panel Meeting Summary Report”, Idaho National Laboratory Next Generation Nuclear Plant Project, Prepared for the DOE Contract DE-AC07-05ID14517, (July 2007).

6. S. Jeon et. al., "A Fundamental Study on Safety Analysis Technology Development of VHTR”, International Conference on Trends in Mechanical and Industrial Engineering (ICTMIE’2011), Bangkok, (Dec 2011).

\section{Additional FMECA references:}

7. "Jet Propulsion Laboratory Reliability Analyses Handbook”, Project Reliability Group, Report: JPL D-5703, July 1990. FEMCA example given in Appendix A. 


\section{LIST OF SYMBOLS, ABBREVIATIONS, AND ACRONYMS}

\begin{tabular}{|c|c|}
\hline AFRL & Air Force Research Laboratories \\
\hline DAG & Defense Acquisition Guidebook \\
\hline DARPA & Defense Research Projects Agency \\
\hline DFX & Design for experiments \\
\hline DoD & Department of Defense \\
\hline DODI & Department of Defense Instruction \\
\hline DOE & Design of experiments \\
\hline EE & Expert elicitation \\
\hline EMD & Engineering and Manufacturing Development \\
\hline FEP & Foundational Engineering Problem \\
\hline FoM & Figure of merit \\
\hline G & Growth rate \\
\hline GAO & Government Accountability Office \\
\hline HIP & Hot-isostatic-press \\
\hline ICME & Integrated Computational Materials Engineering \\
\hline ICMSE & Integrated Computational Materials Science and Engineering \\
\hline IPDT & Integrated Product Development (or Deployment) Team \\
\hline IPQA $^{\mathrm{TM}}$ & In-process quality assurance (trademark of Beyond Six Sigma) \\
\hline JDMTP & Joint Defense Manufacturing Technology Panel \\
\hline KPC & Key process characteristic \\
\hline LRIP & Low Rate Initial Production \\
\hline MAI & Metals Affordability Initiative \\
\hline ManTech & Manufacturing Technology \\
\hline M\&P & Materials \& Processes \\
\hline MRA & Manufacturing Readiness Assessment \\
\hline MRL & Manufacturing Readiness Level \\
\hline MT & Manufacturing Technology \\
\hline NAR & Non-advocate review \\
\hline NDE & Non-destructive evaluation \\
\hline PIRT & Phenomena Identification and Ranking Technique \\
\hline $\mathrm{P} \& W$ & Pratt \& Whitney \\
\hline PPB & Prior particle boundary \\
\hline QC & Quality control \\
\hline $\mathrm{R}$ & Thermal gradient \\
\hline SE & Systems Engineering \\
\hline SEMT & Systems Engineering for Manufacturing Technology \\
\hline RXM & Acronym for the Manufacturing Technology Directorate of AFRL \\
\hline SOW & Statement of Work \\
\hline SwRI & Southwest Research Institute \\
\hline TML & Tool Maturity Level \\
\hline TRA & Technology Readiness Assessment \\
\hline TRL & Technology Readiness Level \\
\hline UQ & Uncertainty quantification \\
\hline $\mathrm{V} \& \mathrm{~V}$ & Verification \& validation \\
\hline
\end{tabular}

